\title{
Contests and unethical behavior in organizations: a review and synthesis of the empirical literature
}

\author{
Simon Piest ${ }^{1}$ [D $\cdot$ Philipp Schreck ${ }^{1}$ (i)
}

Received: 1 July 2019 / Accepted: 14 September 2020 / Published online: 27 October 2020

(c) The Author(s) 2020

\begin{abstract}
Contests are widely used in business contexts because they are believed to increase the effort and performance levels of employees. One negative aspect of contests is that they may provide incentives for unethical behavior aimed at improving one's own position relative to that of competitors. It is therefore important to understand how companies should design contests so as to reduce unethical behavior without reducing the positive effects of contests on employee effort. Research from the social and behavioral sciences can offer relevant insights on this question, as in those fields competition is a subject of sustained academic interest. The aim of this review is to offer a systematic account of the growing literature on contests and unethical behavior and shed light on why and when contests among employees may lead to unethical behavior. To this aim, we also develop a framework for organizing the vast, multi-disciplinary literature in a structured and integrative manner. Through this endeavor, our review identifies several directions for future research.
\end{abstract}

Keywords Behavioral business ethics · Cheating · Competition · Competitiveness · Sabotage $\cdot$ Tournament

JEL Classification M12 $\cdot$ M14 · M52

\section{Unethical behavior in contests}

Many organizations run internal contests in order to induce competition among their employees. They often do this because the incentives associated with competition are believed to increase motivation, effort, and performance (Dechenaux et al.

Simon Piest

simon.piest@wiwi.uni-halle.de

Philipp Schreck

philipp.schreck@wiwi.uni-halle.de

1 School of Law and Economics, Martin-Luther-University Halle-Wittenberg, Halle (Saale), Germany 
2015; Lazear and Rosen 1981). These contests can take many forms. For example, employees compete for bonuses in sales contests (Brown et al. 1998), for promotion (Dechenaux et al. 2015; Lazear and Rosen 1981), or for symbolic awards (Charness et al. 2014). Similarly, many organizations "gamify" tasks in order to conduct performance comparisons within a peer-group (Reeves and Read 2013; Werbach and Hunter 2012).

Experimental research shows that organizational contests can increase the effort and performance of employees. For example, there is evidence that tournament payschemes have strong effects on performance (Delfgaauw et al. 2013; Gneezy et al. 2003; Harbring and Irlenbusch 2003). Recent findings from laboratory and field experiments demonstrate that rankings can boost employee performance even when the ranks are not associated with monetary gains (Azmat and Iriberri 2010; Blanes et al. 2011; Hannan et al. 2008; Kuhnen and Tymula 2012; Tafkov 2013; Tran and Zeckhauser 2012).

The desirable effects of contests are no doubt a main reason why organizations use contests so extensively. However, contests can also produce undesirable effects in that they provide incentives for employees to improve their position relative to that of their competitors by illegitimate means (Belot and Schröder 2013). More specifically, contests may induce employees to employ two generic strategies that we label sabotage and cheating (Preston and Szymanski 2003). Sabotage refers to behaviors that aim to reduce the absolute performance score of a competing colleague. Examples of sabotage at work include locking a colleague's workstation, providing colleagues with false information, or even destroying their work (Charness et al. 2014). Cheating, in contrast, refers to behaviors that involve manipulating one's own absolute performance score. Examples of cheating to improve one's rank include bribery, strategic misreporting, and more generally manipulating the evidence for one's own performance to gain an advantage (Rigdon and D'esterre 2015). Both strategies, sabotage and cheating, lead to the same result-they improve one's own position in the contest. ${ }^{1}$ However, as both clash with commonly accepted behavioral norms such as honesty and fairness, they are considered illegitimate and unethical. Unethical behavior is commonly defined as an act that is harmful to others and runs counter to ethical norms that are widely accepted in a community (Jones 1991).

In the context of organizational design, it is important to develop measures for preventing unethical behavior in otherwise useful contests. To achieve this goal, however, it is necessary to gain a thorough understanding of how contests can lead to unethical behavior in the first place. Research from the social and behavioral sciences can offer relevant insights, as in those fields competition has been a subject of sustained academic interest for quite some time (e.g., Deutsch 1949; Triplett 1898).

\footnotetext{
1 The literature on unethical behavior in contests sometimes lists a third category-collusion (Harbring and Irlenbusch 2003; Preston and Szymanski 2003). Collusion involves agreeing on an outcome with another actor so as to disable the competition. This means that collusion does not meet our criterion of negative goal interdependence (Deutsch 1949). For that reason, our review does not cover research on collusion.
} 
Currently, there is a notable upsurge in experimental research on contests and unethical behavior from the angles of economics (e.g., Conrads et al. 2014; Harbring and Irlenbusch 2011) and psychology (e.g., Kilduff et al. 2016; Pettit et al. 2016). This research has yielded informative and useful findings on the effects of contests on unethical behavior. Although this literature is growing, it has yet to produce a comprehensive account of how contests can cause unethical behaviors. Existing reviews of the literature usually focus on the effects of contests on performance (e.g., Murayama and Elliot 2012). For example, the review of experimental research on contests by Dechenaux et al. (2015) includes only a brief section on sabotage in the context of contests; it does not cover cheating in contests at all. To date, none of the reviews of relevant research offers a comprehensive account of all the factors that influence contests, their effects, and the interplay between contests and unethical behavior in organizations.

The aim of our review is to fill this gap. In doing so, we follow guidelines for writing systematic reviews, such as the one provided by Fisch and Block (2018) and Clark et al. (2020). Our review's main contribution is that it offers a systematic account of the relevant literature that sheds light on why and when contests among employees lead to unethical behavior. A further contribution of our study is the framework we build with the aid of concise and consistent terminology for discussing the ample multi-disciplinary literature in a structured and integrative manner. Finally, in the course of our review we identify promising avenues for future research.

The rest of this paper is organized in four parts. In Sect. 2, we discuss some basic theories that explain the effect of competition on unethical behavior. In Sect. 3, we develop a simple but precise conceptual framework for the analysis of contests and unethical behavior. In Sect. 4, we employ this framework to pursue our main goal; namely, to review and classify systematically the empirical literature on contests and unethical behavior in organizations. In Sect. 5, on the basis of our review, we identify open research questions and avenues for further research on contests and unethical behavior.

\section{Theoretical background: why does competition cause unethical behavior?}

Before we review factors that affect unethical behavior in contests, we should discuss the most prominent theoretical accounts of why competition would cause unethical behavior at all.

There is a straightforward explanation for unethical behavior in contests. People typically want to win, or avoid losing, contests (Dutcher et al. 2015; Gill et al. 2018). That is, they care for their rank in a contest. Consequently, people engage in activities that are likely to improve their rank. Such activities may be legitimate and desired ways of competing, such as when contestants exert more effort in their task. However, other activities, such as sabotage and cheating, are illegitimate and thus undesired. In short, increased effort and unethical behavior may be functional equivalents when participants in a contest have the desire to win. Hence, competition 
causes unethical behavior in the same way as it causes increased effort. This argument is compatible with the most common theories on behavior in contests, that is, tournament theory (the economic perspective) and social comparison theory (the psychological perspective). We discuss both theories shortly below.

\subsection{The economic perspective: tournament theory}

The economic perspective on behavior in contests is typically attributed to Lazear and Rosen (1981; for a review, see Connelly et al. 2014). The theory explains behavior in contests in economic terms. A contest's prize can be monetary but could also be immaterial, such as prestige or privilege (Connelly et al. 2014). The prize is awarded to the contest winner. To increase their chances of winning the prize, contestants put forth effort. In an organization setting, this effort is usually the employees' work effort. The precise amount of effort that contestants put forth is modeled as a function of the incentive structure. The most prominent element of the prize structure is the prize spread (Cardinaels et al. 2018; Harbring and Irlenbusch 2003). The prize spread is the difference between winner and loser prize. In a contest among employees, this is often the wage difference between the current wage and the wage that the winning employee will earn after being promoted.

Working harder or smarter is the legitimate and constructive way of competing (Bracha and Fershtman 2013). However, certain illegitimate forms of effort might also increase the chances for a higher rank. There are innumerable kinds of such illegitimate effort. In this review, however, it will suffice to differentiate between cheating and sabotage. Cheating refers to a manipulation of one's own performance measure in order to improve one's rank. In contrast, sabotage refers to activities meant to impair the performance of competitors (we discuss both behaviors in more detail in Sect. 3.2). While tournament theory research has brought forward other determinants of effort, such as the number of contestants or heterogeneity of contestants, the theory posits that prize spread is the primary determinant of effort (Connelly et al. 2014). But the crucial point here is that the factors that stimulate productive effort may also stimulate destructive effort, such as cheating and sabotage.

\subsection{The psychological perspective: social comparison theory}

As discussed above, the economic account of contestant behavior acknowledges that a prize does not need to be monetary but can also be "prestige". From a psychological perspective, it is important to acknowledge the difference between the material value of a prize and the immaterial value of being better than one's peers. Consequently, the prize itself constitutes only a part of an employee's motivationand that motivation would exist even in the absence of competition (e.g., piece rate incentives). The other part-the motivation unique to competition-is the value of winning and being better than one's peers. In line with this argument, the desire to win and be better than others stimulates effort, too. This has been demonstrated by empirical research: the presence of rankings can increase effort even when winning is not associated with a material prize (Azmat and Iriberri 2010; Blanes et al. 2011; 
Hannan et al. 2008; Kuhnen and Tymula 2012; Tafkov 2013; Tran and Zeckhauser 2012).

The social comparison theory (Festinger 1954) is often cited as a psychological explanation for the effect of competition on effort (Garcia et al. 2013). But the theory is able to explain unethical behavior in contests just as much (Edelman and Larkin 2014). According to Festinger's theory, people have a need for accurate selfevaluations. They attain such evaluations by engaging in social comparisons-for example, by comparing their abilities with the abilities of peers. But people do not only want to know how they compare with others. Rather, they have a general drive to improve-something that Festinger (1954) coined the "unidirectional drive upwards" (p. 124). Accordingly, people derive positive self-evaluations and feelings of self-worth from performing better than peers (Garcia et al. 2013). Neuro-physiological research shows that favorable social comparisons, of which winning is a prime example, stimulate the human reward system (Fliessbach et al. 2007). This is what Dohmen et al. (2011) call the "joy of winning" (p. 280).

In sum, winning contests is associated with feelings of joy and positive self-evaluations. People will therefore behave in ways conducive to winning. As argued earlier, some of these ways are legitimate. But usually people also have the possibility to engage in unethical behavior that will promote winning. Hence, in terms of the social comparison theory, competition causes people to increase their productive efforts, but likewise, competition can cause unethical behavior, if that helps attaining the goal of winning.

There is one crucial difference between legitimate strategies and unethical behavior in contests. Unethical behavior corresponds to a violation of widely accepted norms such as fairness and honesty, and hence involves psychological costs (Schreck 2015). To complete our theoretical discussion of the competition-unethical behavior link, the last subsection explores theoretical arguments for why competition may lower the psychological costs of unethical behavior-and thus make it more likely.

\subsection{Competition and the psychological costs of norm violation through unethical behavior}

The argument that competition might lower the psychological costs of unethical behavior rests on the notion that it diminishes the salience of social preferences in general. Since in a contest one person's achievement implies his or her competitors' failure, competition does affect one's perception of how he or she relates to others (Johnson and Johnson 1989). Contests can create such severe rivalry among competitors that the mere desire to beat others increases the likelihood of unethical behavior (Deutsch 1949; Johnson and Johnson 1989; Kilduff et al. 2016). As Helen Lewis argued in an early study in this context:

"Competition [...] involves a heightening of ego-demands so that the egoobjective is more important than any common objective; i.e., the person is at the focus of consciousness, self-consciousness is at a maximum-the individual is "on the spot"- so that similar behavior may be expected from the 
member of the competing group and the person driven by inordinate (neurotic) ambition" (Lewis 1944, p. 115).

Similarly, more recent work on decision making suggests that individuals are less concerned about ethical standards when they judge a situation to be competitive (Butterfield et al. 2000; Messick 1999). This shift in the relative importance of ethical concerns might be attributed to different sorts of affects that are typical for contests characterized by intense rivalry (Kilduff et al. 2016; Malhotra et al. 2008; Pierce et al. 2013). If competition heightens perceived rivalry it is likely to decrease the moral costs of norm violation, if the desire to win lessens the competitors' aversion to using unethical behaviors as a means towards the end of beating the others (To et al. 2020).

In this section, we argued that if people have a preference for ranking high in a contest, and if unethical behavior can help them improve their rank, then competition will make unethical behavior more likely. We also argued that in competitive situations, the psychological costs of norm violations will diminish, which is another reason for why competition may lead to unethical behavior. In what follows, we will review the literature on contests and unethical behavior in organizations.

\section{A framework for organizing research on unethical behavior in contests}

In our literature review we will discuss empirical studies that investigate why and under which conditions contests can lead to unethical behavior. The focus of these studies varies. For example, some studies focus on situational forces that can cause unethical behavior, while others focus on personality characteristics that make people more prone to behaving unethically. To gain a clear picture of the range of reasons for unethical behavior that these studies propose, we introduce a simple framework that allows us to organize the literature systematically and structure the discussion accordingly. We use this framework to categorize the triggers of affective states that drive unethical behavior in contests. Personal and situational attributes may be conceived as moderators of the effects that specific contest attributes have on affective state (see Fig. 1).

The basic structure of our framework essentially reflects a person-situation interactionist view of behavior (Lewin 1935; Treviño 1986). More specifically, it encompasses empirically tested variables associated with affective competitive state and variables associated with unethical behavior in the context of competition. This framework aggregates and condenses these variables into a small number of core aspects that influence the effect of contests on unethical behavior. We derived our framework in the course of screening and organizing the literature, rather than from a particular theory, following a bottom-up approach (for comparable uses of research frameworks, see Joos 2019; Thomas 2018). Hence, we did not impose any restrictions on the variables to be included in the framework-all variables that were studied in the included studies are represented in the framework. While building the framework, we sought to address the lack of consistent and clear terminology in 


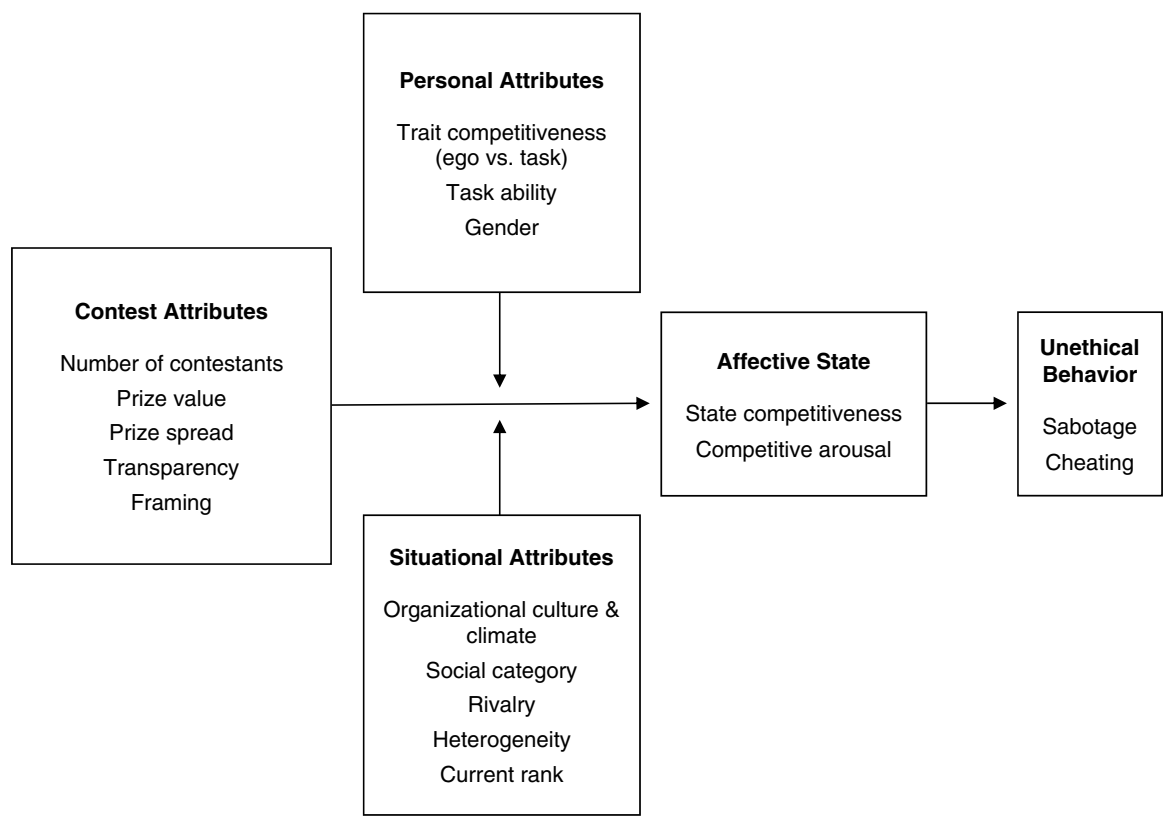

Fig. 1 The framework we used to organize our review and visualize how contests may cause unethical behavior

the literature on competition. To date, there is no consensus on how competition in a broader sense should be conceptualized. The same terms are often used to refer to different concepts, while different terms are sometimes used to refer to similar concepts. This may be attributed partly to the fact that different researchers approach this topic from diverse backgrounds. Nevertheless, in order to integrate their findings, it is necessary to unify the language in which these concepts are discussed. For that purpose, we will first clarify the key concepts we employ in our review and in our framework and then proceed to review the literature on unethical behavior in contests with the aid of our framework.

\subsection{Contest attributes}

Organizations usually establish competition among their employees in the form of institutionalized contests; that is, evaluation and incentive schemes based on the employee's performance relative to the performance of co-workers (Arora-Jonsson et al. 2020). The terms "competition" and "contest" require some further clarification, however.

The term "competition" has been used with diverse meanings in the literature. As Stanne et al. (1999, p. 134) point out in their early meta-analysis of the effects of competition on motor-skills performance, "competition has been defined as a situational variable, a cognitive variable, a trait, a motive, or an attitude." Despite the many studies conducted since then, consensus on the definition of competition has 
yet to be reached. For instance, Hanek et al. (2016) and Schurr and Ritov (2016) have used the term "competition" to refer to organizational contests. Others, such as Schreck (2015) used the same term to describe the general structure of interaction that is typical of contests; yet others, such as Cartwright and Menezes (2014), to allude to the number of competitors, describing a large number of competitors as "high competition." In this review we follow the classic and simple definition by Deutsch (1949, p. 132), who described competition as a structure of interaction that is characterized by negative goal interdependence. In such a situation two or more actors share a goal whose achievement by either actor automatically implies that the other actor has failed to achieve it.

In order to avoid ambiguity as much as possible, we will use the term "competition" to refer exclusively to the general structure of negative goal interdependence (Deutsch 1949). To refer to a planned, institutionalized instance of competition, we will use the term "contest." According to our definition, contests are events; that is, concrete manifestations of competition. A contest occurs between two or more parties, the contestants. All contestants pursue the same goal, but that goal cannot be attained by all contestants. Examples of contests in organizations include sales contests, employee rankings, and promotion tournaments (Grote 2005; Lazear and Rosen 1981; Poujol et al. 2016; Vriend et al. 2016).

Contests can be characterized in terms of various attributes, such as the number of contestants or the value and spread of prizes (see Fig. 1). A contest's attributes make up its overall design and are usually deliberately defined by executive managers. As we will see, whether contests can potentially lead to unethical behavior and in what way depends on the exact design of a contest; that is, on the contest's attributes. Contest attributes constitute the first main component of our framework.

\subsection{The behavioral outcome-Unethical behavior in the form of sabotage and cheating}

Our framework's second component is the unethical behavior. Employees are expected to use legitimate means to achieve superior performance in contests. However, employees may also use illegitimate strategies to get ahead in a contest. The behaviors associated with these strategies fall within one of two categories; namely, sabotage or cheating.

Sabotage refers to costly activities that employees carry out in order to impair the performance of competitors; for instance, by spreading negative rumors about them (Chen 2003; Lazear 1989). Sabotage among employees is always undesirable because it reduces overall output (Chen 2003; Chowdhury and Gürtler 2015). In fact, as a result of sabotage, output may become considerably smaller than it would have been without a tournament incentive system (Carpenter et al. 2010). In contrast, the aim of cheating is to manipulate one's own performance measure so as to improve one's rank (Charness et al. 2014; Chen 2003). For example, a manager who employs fraudulent accounting to increase his or her ostensible output cheats for personal benefit (Berentsen and Lengwiler 2004). 
Experimental research on how the presence or absence of competition affects sabotage shows that competition increases the occurrence of sabotage (Harbring and Irlenbusch 2011). This is the case even when winning is not associated with any material gain, which indicates that the causes of behavioral responses to competition are not confined to monetary incentives. Employees attach value to the social status associated with their rank, even in the absence of immediate tangible benefits. This value appears to be sufficiently high for employees to accept the moral costs of unethical behavior (Charness et al. 2014; Hartmann and Schreck 2018; Schreck 2015).

\subsection{Personal attributes}

How different employees respond to contests varies. The behavioral effects of a contest depend on various contingencies and factors, including personality characteristics. The personal attributes of a contestant constitute the third core component of our framework. Whether employees will behave unethically or not in a contest is partly determined by personal attributes, such as their general preference for or aversion to competition, their gender, and the degree to which they are familiar with the task. An attribute that is particularly widely discussed in the literature is a person's attitude towards competition, a construct we label trait competitiveness. Trait competitiveness captures the extent to which someone likes or dislikes competing. It is a personality characteristic and as such it changes only slowly, if at all, over a person's lifetime (Hamaker et al. 2007; Harris and Houston 2010).

The term "competitiveness" refers to different concepts in the literature. Some researchers use it to refer to a personality trait that reflects a person's general desire to win (Houston et al. 2015; Newby and Klein 2014; Smither and Houston 1992). Others use the term to refer to a "competitive situation" (Harbring and Irlenbusch 2003, p. 447) or to "competitive environments" (Cartwright and Menezes 2014, p. 56) that are encountered in a "competitive institution," such as a specific university (Gneezy et al. 2003, p. 1053). Yet others use the term "competitiveness" to indicate the extent to which two particular competitors go head-to-head, based on past performance (Kilduff et al. 2010). In our review, we apply the most prevalent usage, in which "competitiveness" is understood as a personality characteristic. In previous studies, trait competitiveness has been mostly conceptualized as either one-dimensional or two-dimensional. ${ }^{2}$ We will discuss these concepts in more detail when we review the corresponding empirical evidence in Sect. 4.3.1.

\subsection{Situational attributes}

As we point out above, the behavioral effects of a contest can vary from one person to another. Importantly, these effects can also vary from one situation to another,

\footnotetext{
2 Occasionally, trait competitiveness has also been conceptualized as multi-dimensional (Franken and Brown 1995; Newby and Klein 2014).
} 
even for the same contestant. The attributes of a situation that may affect whether an employee will behave unethically or not in a contest and to what extent constitute the fourth major component of our framework. For example, the degree to which employees respond to competition in unintended ways depends on characteristics such as organizational climate, the presence and design of monitoring systems, and the arguments that legitimize the use of competitive incentive systems in the organization. Another important situational factor is the personal relationship between the contestants; in particular, whether they have a history of having been involved in head-to-head situations with another contestant (Kilduff et al. 2010). ${ }^{3}$

\subsection{Affective states: state competitiveness and competitive arousal}

So far, we have considered the direct link between competition and unethical behavior and how this link may depend on personal and situational attributes. In this section we will take into account the motivational mechanisms that explain exactly how contests can lead to unethical behavior (e.g., Hartmann and Schreck 2018; Kilduff et al. 2016). The fifth component of our framework comprises variables that describe an employee's affective responses to competition, which we refer to as affective state.

In general, researchers often refer to affective responses to explain how certain stimuli can have behavioral consequences (Elfenbein 2007; Oreg et al. 2016). Affective states are psychophysiological constructs that consist of various dimensions (Harmon-Jones et al. 2013). We should note that affective states are transient and depend on the situation as well as on the personal characteristics of the actors involved (Hamaker et al. 2007; Steyer et al. 2015). The literature provides various concepts that describe an actor's state during competition, including "comparison concerns" (Garcia et al. 2013, p. 235), "desire to win" (Malhotra 2010, p. 139), "motivation to win" (Kilduff 2014, p. 944), "competitive motivation" (Garcia and Tor 2009, p. 871), "competitive arousal” (Ku et al. 2005, p. 89; Nichols 2012, p. 192), and "performance orientation" (Kilduff et al. 2016, p. 1513).

Within the component "affective states," we distinguish between two elements in particular: competitive arousal, which is a response marked by physiological changes, and state competitiveness, a motivational state that corresponds to the desire or motivation to win. These variables can be regarded as psychological explanations of the effect that competition has on unethical behavior.

To summarize, the framework we propose reflects five major elements of the literature on unethical behavior in contests: (a) the characteristics of the contest, (b)

\footnotetext{
3 The term "rivalry" has been used to describe a specific relationship between two competitors (Kilduff et al. 2010) or a form of fierce competition in which a competitor is focused on beating the opponent at any cost (Hartmann and Schreck 2018; Mead 1961). In other contexts, the terms "rivalry" and "competition" are used interchangeably (e.g., Brandts et al. 2009). Malhotra (2010) operationalized rivalry as the number of participants in a contest, where more contestants are associated with less rivalry. In this review, we follow the work of Kilduff et al. (2010) and understand rivalry as the special relation between two competitors with a shared history of head-to-head situations, i.e., contests in which the two rivals performed similarly.
} 
the contestant's personal attributes, (c) the situational attributes, (d) the contestant's current affective state, and (e) the resulting unethical behavior. In the next section, our framework is used to organize the review of the empirical literature on contests and unethical behavior. As we argued earlier, it is important to employ a consistent terminology. Table 1 summarizes the definitions of the key concepts we apply in this review.

\section{Review of the empirical literature on unethical behavior in contests}

\subsection{Literature search strategy and inclusion criteria}

Before we embarked on screening the literature, we defined the criteria that would qualify a study for inclusion in our review. We decided that we would include studies that (a) are empirical, (b) focus on how individuals act and interact in contests, and (c) examine the variables that may determine whether an individual will exhibit sabotage or cheating behavior in such situations. We started with a systematic keyword search in the databases EconLit and Business Source Complete on the EBSCOhost platform. This preliminary search enabled us to derive a starting sample of relevant studies. Specifically, to identify research on competition as a setting, we looked for studies that included at least one of the following terms in the title: compete $^{*}$; contest $^{*}$; tournament ${ }^{*} ;$ rank $^{*}$. Moreover, to identify research on the outcomes on unethical behavior, studies were required to have at least one of the following terms in the title: unethical*; ethic $^{*}$; immoral*; moral*; sabotag*; cheat*. Lastly, to exclude articles that focused strictly on competition between organizations (i.e., market competition), the search results had to contain additionally at least one of the

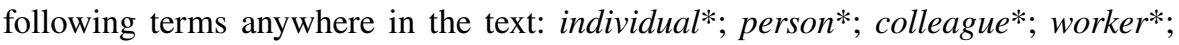
employe $^{*}$. The language was restricted to English. To avoid publication bias, we considered publications not only in peer-reviewed journals but also in other academic journals, as well as working papers. This search yielded 171 results (up to December 1, 2019).

In the next step, we scanned the extracted abstracts and identified 17 articles that satisfied our inclusion criteria; that is, each of these articles was an empirical study on the determinants of unethical behavior in inter-individual competition. Starting from this set of articles, we identified by means of forward and backward tracing another 19 articles that qualified for inclusion. Our initial search did not capture those additional articles either because the respective journals were not related to economics (e.g., the study by Veldhuizen Van Zanten et al. 2002 is published in Psychophysiology) or because the relevant (to our review) terms in the titles referred to specific unethical behaviors that we had not included among our search termsfor example, lying/honesty (Schreck 2015) or salesperson deviance (Jelinek and Ahearne 2010). Our review is therefore based on a total of 36 empirical studies. 


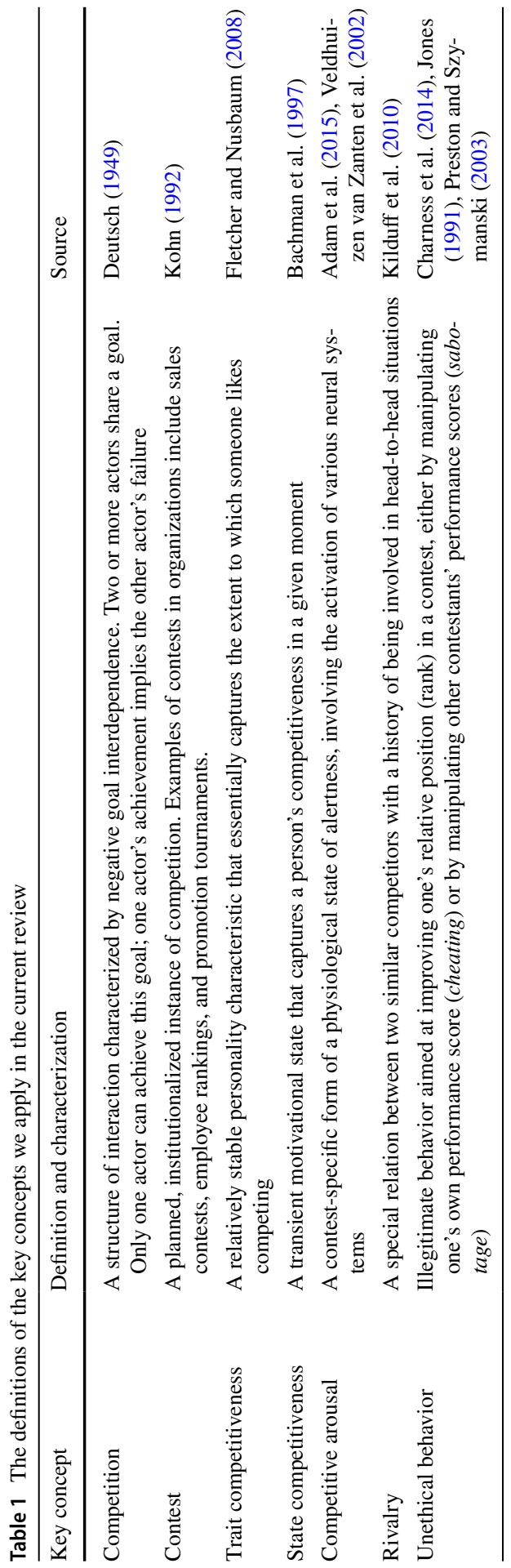




\subsection{Contest attributes}

Lazear (1989) warns that organizations should not introduce contests in the form of tournaments without considering the specific circumstances in which a contest is to take place. For example, cooperation among employees may be too important for the organization to jeopardize by introducing competition. We argue that it is equally important to examine exactly how a contest is designed. There are multiple attributes that characterize a contest, such as the number of contestants, the distribution of prizes (i.e., the prize spread), and the provision of intermediate feedback on ranking. There is considerable research on the effect of many of these attributes on employee performance and of some of these attributes on unethical behavior. We will be discussing the latter in greater detail in the following sections. ${ }^{4}$

\subsubsection{Number of contestants}

A smaller number of contestants is associated with higher performance; this phenomenon has been nicknamed the "n-effect" (Dechenaux et al. 2015; Garcia and Tor 2009; Vandegrift and Holaday 2012). Some theoretical research suggests that a small number of contestants may also be related to a higher degree of sabotage (Gilpatric 2011). The explanation for this idea is that sabotage simultaneously produces negative externalities for the victim and positive externalities for all other contestants (Chowdhury and Gürtler 2015; Konrad 2000). In other words, all contestants (except for the victim) gain the same advantage as the saboteur. Moreover, as group size increases, the number of competitors that the saboteur needs to undermine in order to significantly improve his or her chances of winning also increases and, as sabotage is costly, this strategy becomes less attractive. However, these clear theoretical predictions about the link between group size and sabotage have yet to be tested (Chowdhury and Gürtler 2015).

In the case of cheating, the situation looks somewhat different. Cheating creates a negative externality for all other contestants because it reduces the other contestants' probability of winning (Konrad 2000). This suggests that cheating is not related to group size or that if there is a relation between cheating and group size, this should be positive, because in larger groups the negative externality affects more competitors (Konrad 2000). Harbring and Irlenbusch (2008) have tested this prediction. They conducted an experiment with groups of one principal plus two, four, or eight agents who chose how much costly effort to expend and what level of "sabotage" to engage in. In their experiment, however, an agent's decision to engage in sabotage entailed negative externalities for all other contestants, so the saboteur was the only one who benefited from his or her behavior. Arguably, therefore, this setup

\footnotetext{
${ }^{4}$ We acknowledge that there are other, more general determinants of unethical behavior, such as the possibility of being punished when caught cheating or the likelihood of getting caught as such (Gilpatric 2011). However, an extensive discussion of these factors is beyond the scope of the paper, because they represent general strategies associated with decreased unethical behavior that are not specific to contests. For an overview of punishment in organizations, we refer the reader to Treviño (1992) or Balliet et al. (2011).
} 
resembles more a case of cheating than of sabotage (Chowdhury and Gürtler 2015). In line with the prediction that cheating is not related to group size, Harbring and Irlenbusch (2008) found that the number of contestants had no effect on the decision to engage in or refrain from unethical behavior.

\subsubsection{Prize value}

A key attribute of any contest is the prize value; that is, the total value of the prizes to be awarded. A high prize value motivates participants to exert greater effort in contests (Harbring and Irlenbusch 2011). In light of this, it is worth investigating how prize value relates to unethical behavior. Empirical evidence indicates that the total prize value is not a predictor of unethical behavior in contests. Harbring and Irlenbusch (2011) conducted a study with groups of three agents and one principal. The principal could decide whether he or she would run a contest with a high or a low prize value. The prize spread remained constant in both conditions (e.g., the winner's prize was always 48 units higher than the loser's prize). The authors' data indicate that the prize value had no effect on the level of sabotage the agents chose to engage in.

\subsubsection{Prize spread}

One of the most extensively researched contest attributes is prize spread; that is, the distribution of prizes that can be won in a contest (Falk et al. 2008; Lazear and Rosen 1981). In a simple contest between two individuals with a given total prize value, the largest possible prize spread translates into awarding $100 \%$ to the winner and $0 \%$ to the loser, whereas a very small prize spread would be accomplished by awarding $51 \%$ of the total prize value to the winner and $49 \%$ to the loser. It has been demonstrated that, in contests, larger prize spreads stimulate not only greater effort (Garicano and Palacios-Huerta 2005; Harbring and Lunser 2008; Lazear and Rosen 1981), but also more unethical behavior. Various laboratory experiments have shown that agents choose higher levels of sabotage when the prize spread increases (Falk et al. 2008; Harbring and Irlenbusch 2005, 2011; Vandegrift and Yavas 2010).

Further evidence for the effect of prize spread on sabotage comes from a field study on soccer matches (Garicano and Palacios-Huerta 2005). Before 1994, soccer teams around the world received two points for winning a match, one point for a tie, and no points for losing. In 1994, the rules were changed in some parts of the world, so that the winning team received three points while the losing team received zero points. The prize spread was thus increased. As the new rules applied only in specific parts of the world, some teams played according to both rules in the same season, depending on where the match took place. The results of this natural experiment confirm that the increased prize spread led the players to exert more effort, but also to engage in more sabotage in the form of so-called "dirty play" (Garicano and Palacios-Huerta 2005).

Experimental evidence also points to a link between prize spread and cheating. For example, Conrads et al. (2014) and Feltovich (2019) found that subjects overstate their performance in contests with larger prize spreads. However, the findings 
of Cartwright and Menezes (2014) contradict the positive relation between prize spread and cheating. The authors manipulated prize spread in a lab experiment by awarding bonus payments of $£ 5$ either to the best six (small prize spread) or to the top two (large prize spread) out of 15 contestants. Part of the results is that subjects cheated more when the prize spread was small. However, the effect of prize spread in this study may be confounded by the total prize value, which was $£ 30$ in the first case and $£ 10$ in the second, and by the chances of winning a prize, which amounted to $6 / 15$ in the first setting and to $2 / 15$ in the second.

\subsubsection{Transparency}

Someone who considers sabotaging a competitor to gain an advantage needs to be aware of both his or her own rank and of the rank of the competitor(s). If this information is withheld from contestants (e.g., Konrad 2000), they will not know whom to sabotage. Sabotaging someone who ranks low, or at least below a contestant's own rank, can be regarded as a waste of resources. In contrast, the top-ranking contestants are the most dangerous competitors and therefore the likeliest victims of sabotage (Gilpatric 2011; Gürtler et al. 2013).

Gürtler et al. (2013) conducted a "chosen effort" experiment to test the hypothesis that less transparency on ranks will result in lower levels of sabotage (Gilpatric 2011; Gürtler et al. 2013). The subjects were arranged in groups of three contestants. The authors manipulated whether the contestants would be able to observe each other's effort choices (and therefore each other's rank) or not before the contestants decided whether they wanted to sabotage one of the others. The results of this experiment confirmed that there is a link between the degree of effort a contestant exerts and the likelihood of this contestant being sabotaged. The subjects whose high degree of effort could be observed were sabotaged by the other contestants. However, when the contestants had no information about their competitors' effort levels, they did not know whom to sabotage, so effort was no longer related to the likelihood of being sabotaged. Interestingly, the participants were more willing to expend a higher degree of effort when information about the other competitors' performance was concealed. The authors do not clarify, however, whether withholding information on the competitors' effort level reduced the overall level of sabotage or whether it led to the more equal distribution of the same level of sabotage.

\subsubsection{Framing}

Another contest attribute that has been empirically tested is how a contest is framed. "Framing" refers to different ways of designing the structure of choices available to the contestants, which influences how the contestants perceive a competition. For example, calling the practice of sabotage by its name and describing explicitly what it involves appears to reduce that kind of unethical behavior. Harbring and Irlenbusch (2011) conducted a laboratory experiment in which participants had the option to sabotage each other. In one condition, this option was explicitly called "sabotage," while in another condition the term "sabotage" was avoided and the respective options had neutral labels. It turned out that using the term "sabotage" 
was enough to reduce the occurrence of the practice. Framing did not have any effect on effort in that experiment.

Pettit et al. (2016) provide another example of how framing affects behavior. In their experiments on competition and cheating, the authors framed otherwise identical contests in two different ways. In one setting, the contest was framed as a chance to gain status by getting ahead of competitors; in the other setting, the contest was framed as a risk of losing status by falling behind others. In all variations of this experimental design, the participants were more inclined to cheat in order to avoid losing status rather than in order to gain status. Although several studies investigate the effect of gain and loss framing on unethical behavior, cheating in particular (Grolleau et al. 2016; Kern and Chugh 2009; Schindler and Pfattheicher 2017), the study by Pettit et al. (2016) remains the only one to date that focuses on unethical behavior in contests.

\subsection{Personal attributes}

\subsubsection{Trait competitiveness}

Trait competitiveness is a relatively stable (i.e., constant) personality characteristic (Hamaker et al. 2007; Harris and Houston 2010). It has been mostly conceptualized as either one-dimensional or two-dimensional: one-dimensional trait competitiveness essentially captures the extent to which someone likes competing and two-dimensional trait competitiveness reflects two distinct types of motivation for competing. We elucidate both concepts below.

One-dimensional trait competitiveness can be described as a "pure taste for having the best rank in the performance distribution" (Charness et al. 2014, p. 39) or an individual's propensity to join and enjoy a contest (Fletcher and Nusbaum 2008; Martens 1975). In contrast to state competitiveness, which reflects preferences with regard to winning contests in a given moment, one-dimensional trait competitiveness describes a consistent and enduring preference for winning contests. Most definitions of one-dimensional trait competitiveness describe it as the desire to win and be better than others in interpersonal situations (e.g., Harris and Houston 2010; Helmreich and Spence 1978; Houston et al. 2002; Smither and Houston 1992; Spence and Helmreich 1983). Similar concepts include "dispositional competitiveness" (e.g., Bachman et al. 1997, p. 204; Veldhuizen Van Zanten et al. 2002, p. 760), "competitive orientation" (Smither and Houston 1992, p. 408), and "intentional competition" (Kohn 1992, p. 3). Trait competitiveness is usually assessed with psychometric scales. We provide an overview of the scales that were used in the reviewed studies on trait competitiveness and unethical behavior in Table 3 (“Appendix").

The literature we review here points to a link between trait competitiveness and unethical behavior (Jelinek and Ahearne 2010; Terpstra et al. 1993). Jelinek and Ahearne (2010) found a positive relationship between one-dimensional competitiveness and sabotage, e.g., in the form of criticizing colleagues at the workplace. Terpstra et al. (1993) assessed one-dimensional trait competitiveness in their study on insider trading. Subjects who scored higher on trait competitiveness also chose 
the unethical options more often. The authors concluded that "highly competitive individuals have an intense desire to compete and win [and this] may override the perceived importance of the ethicality" (Terpstra et al. 1993, p. 384).

Two-dimensional trait competitiveness accounts for the differences in the goals that competitors have. Some employees compete mainly for the sake of winning and being the best: beating their colleagues is their primary interest, while mastering the task at hand is of secondary significance (Horney 1936; Ryckman et al. 1990, 1994). We call this dimension ego trait competitiveness. Other employees, however, compete primarily for the sake of self-improvement as well as mastering and enjoying the task at hand. For such people, beating competitors is of secondary importance and ranking serves mainly as a way of assessing the extent to which they have mastered their task (Mudrack et al. 2012; Ryckman et al. 1996). We call this dimension task trait competitiveness. In sum, two-dimensional trait competitiveness comprises ego trait competitiveness and task trait competitiveness (Nicholls 1984).

The distinction we outline above is based on earlier two-dimensional conceptualizations of trait competitiveness. For example, Ryckman et al. (1997, p. 271) distinguish between "hypercompetitiveness" and "personal development competitiveness" while Griffin-Pierson (1990, pp. 108-109) differentiates between "interpersonal competitiveness" and "goal competitiveness"; similarly, Franken and Brown (1995, p. 175) differentiate between "ego-orientation" and "task-orientation" and Tassi and Schneider (1997, p. 1557) between "other-referenced competition" and "taskoriented competition." Based on a factor analysis of various competitiveness scales, Houston et al. (2002) differentiate between "self-aggrandizement" and "interpersonal success." We adopt the terms "ego competitiveness" and "task competitiveness" because they are most succinct and, in our view, capture the dimensions most aptly (Franken and Brown 1995; Nicholls 1984).

It is not clear from the literature how the two dimensions of trait competitiveness interrelate. While some research indicates that ego trait competitiveness and task trait competitiveness are positively correlated (Tassi and Schneider 1997), other studies find no correlation (Ryckman et al. 1997) or even that they are negatively correlated (Franken and Brown 1995).

Differentiating between the two dimensions of trait competitiveness enables researchers to refine their predictions of whether actors will behave unethically in contests or not. For example, ego-competitive employees may achieve their primary goal-beat their opponents-more easily by unethical means such as cheating or sabotage. In contrast, the primary goal of task-competitive people would be to master the task at hand in the best possible way and to further their personal development (Ryckman et al. 1996). In the latter case, neither cheating nor sabotage contributes to achieving this goal. Consequently, one would expect the effect of competition on unethical behavior to be particularly strong among highly ego-competitive people but absent or even negative among people who are highly task-competitive (Mudrack et al. 2012).

Mudrack et al. (2012) studied empirically the relation between two-dimensional trait competitiveness and unethical behavior. In their experiment, the subjects were asked to read three vignettes in which the actor made a direct gain at the expense of others and then to judge whether the actor's behavior was ethical or not and to 
estimate how likely they were to engage in such behavior themselves. Mudrack et al. (2012) found that ethical judgments and behavioral intentions are negatively related to ego trait competitiveness but positively related to task trait competitiveness (see Table 3 in the "Appendix" for an overview of the instruments used to assess trait competitiveness). Beu et al. (2003) assessed ethical intent through two different scenarios: bribery in a business context and cheating in an academic context. In contrast to Mudrack et al. (2012), Beu et al. (2003) found no relation between task trait competitiveness and ethical intent. Unfortunately, these authors did not assess ego trait competitiveness. More research is needed to determine how task trait competitiveness and ego trait competitiveness influence the effect of competition on unethical behavior.

\subsubsection{Task ability}

It goes without saying that people's ability to perform a task is related to how they will perform that task. Interestingly, task ability also is related to whether contestants will behave ethically or unethically. For example, experimental research by Schwieren and Weichselbaumer (2010) find that people who are not able to complete a task successfully will cheat, possibly in an attempt to save face. This intuitive finding has been corroborated in field studies. For example, soccer teams whose ability is lower than that of the competing team commit more fouls and thus engage in more sabotage (e.g., Deutscher et al. 2013). Similarly, less qualified judokas tend to sabotage more qualified opponents (Balafoutas et al. 2012). In contrast to these findings, however, in the experiment that Vandegrift and Yavas (2010) ran, which involved a real-effort task, subjects of lower ability did not engage more in sabotaging opponents than subjects of higher ability. Nevertheless, the literature predominantly suggests that lower task ability is associated with a higher degree of unethical behavior. Other research implies that subjects take their competitors' ability into account when they decide whether to sabotage or cheat (Deutscher et al. 2013; Deutscher and Schneemann 2017; Frick et al. 2008; Harbring et al. 2007). We will discuss this research in Sect. 4.4 (situational attributes) under the heading "Heterogeneity."

\subsubsection{Gender}

There is considerable evidence that men and women react differently to competition. Gender differences have been investigated mainly in the context of performance outcomes (Gneezy et al. 2003; Gneezy and Rustichini 2004; Saccardo et al. 2018; for a review, see Niederle and Vesterlund 2011). A few studies, however, focus specifically on gender differences in how competition and unethical behavior interrelate. These studies show that men are more inclined than women to engage in sabotage or to have unethical intentions in response to competition (Dato and Nieken 2014; Hartmann and Schreck 2018; Nieken and Dato 2016; Schreck 2015; Terpstra et al. 1993).

At closer inspection, it appears that these gender differences could be ascribed to differences in task ability, personality, or the expectation of being sabotaged by an 
opponent. Schwieren and Weichselbaumer (2010, p. 245), for example, found that women cheated slightly more than men, but the authors attributed this difference entirely to differences in task ability-men happened to perform better in that particular maze task. Another variable that may explain gender differences in contests is trait competitiveness: gender-related differences that have been measured on various trait-competitiveness scales indicate that men like competing more than women do (Gill 1986; Helmreich and Spence 1978; Hibbard and Buhrmester 2010; Houston et al. 1992; Smither and Houston 1992). Finally, Dato and Nieken (2014, 2020) found that the gender differences they found in their research also stem from different expectations about the likelihood of being sabotaged by opponents: in their study, men were more likely than women to expect their opponents to sabotage them. The authors argue that this expectation may have caused male participants to engage more in preemptive counter-sabotage than female participants did.

To summarize, there is evidence that both genders cheat when they know that they are not as good as their opponents at a particular task and that their chance of winning without cheating is very low (Deutscher et al. 2013). However, some studies have found evidence that differences in unethical behavior in contests are related to gender. These differences are probably mediated by other variables that vary between genders, such as trait competitiveness, the ability to perform the experimental task, or the expectation of being sabotaged by the opponent.

\subsection{Situational attributes}

\subsubsection{Organizational culture and climate}

Brown et al. (1998) demonstrated that employees react differently to the same contest, depending on how they perceive the company's competitive climate. Similarly, Murayama and Elliot (2012) found that how contestants perceive environmental competitiveness affects their behavior during contests. These findings are indicative of the role that organizational culture plays in the relationship between competition and behavior. Organizational culture is understood as the set of values and implicit rules that an organization's employees refer to, particularly in ambiguous situations (Arnaud and Schminke 2012; Loe et al. 2000; Treviño 1986). For example, if the organizational culture stresses the importance of winning, employees may feel under pressure to win at any cost and consequently employ unethical behaviors. Experimental evidence reveals that the need to conform to group norms explains why contestants who believe that condoning dishonesty is the group norm will behave dishonestly (Aydogan et al. 2017).

Reproducing organizational culture in the laboratory is admittedly difficult; however, researchers have used survey-based studies to examine how employees perceive prevalent attitudes and norms in their organization. In their survey at a car dealership, Hochstein et al. (2017) found that whether salespeople behaved unethically towards a customer depended on how they perceived the company's attitude to competitiveness. More specifically, the salespeople who perceived the climate at 
the dealership as competitive were less honest in their advice to customers so as to increase their chances of closing a deal.

Poujol et al. (2016) obtained similar results from a study in the banking sector. These results suggest that employees who perceived the contest's climate as unethical were more susceptible to unethical behavior. Managers may try to counteract such behavior by stressing that the organization is customer-oriented and promoting an ethical climate. However, such measures may not be enough, so long as perceptions of the organization's climate as competitive persist. On the basis of their findings, Hochstein et al. (2017) argue that, while efforts to comply with an ethical climate can strengthen the salespeople's ethical intentions, the goal of conforming to an ethical climate contradicts the goal of conforming to a competitive climate and the resulting depletion of cognitive resources may ultimately increase unethical behavior. Despite these findings, it is worth noting that recent meta-analytic studies found that cognitive depletion has no consistent effect on dishonesty when dishonesty inflicts harm on concrete others (Köbis et al. 2019).

\subsubsection{Social category}

According to social categorization theory, every person belongs to multiple social groups or categories. For example, a man may belong to the categories "men," "Germans," "sportsmen," and "fathers" (Hogg and Terry 2000; Tajfel and Turner 1979). In the context of contests, a social category may be made salient if it is explicitly highlighted. Garcia et al. (2013) argue that which of these categories is made salient in a contest affects competitive behavior (i.e., effort). By extension, this argument also applies to unethical behavior: if, for example, a social category that is associated with a high degree of competitiveness is made salient in a contest, the effect of this contest attribute on state competitiveness and arousal may be particularly strong. For example, making the social category "male" salient in a contest (e.g., by reminding male contestants of their sex) may lead to higher levels of state competitiveness, because men are expected to be more competitive than women (Rosenkrantz et al. 1968). Moreover, emphasizing the differences between the distinct social groups to which contestants belong may lead one group to exert greater effort to positively differentiate itself from another group (i.e., from an outgroup). These processes, which are described as "outgroup discrimination," lead contestants to focus on achieving superiority; that is, winning (Tajfel et al. 1971), and may ultimately stimulate unethical behavior. Examining this idea, Charness et al. (2014) found that while contestants who belong to the same school sabotage each other less than contestants who belong to different schools, they cheat more than contestants who belong to different schools, so, the evidence from this study is mixed.

The above example illustrates that some of the variables we review here can have very different effects, depending on the context: for instance, on the one hand, similarity (belonging to the same school) can be a source of rivalry and increase unethical behavior in the form of cheating (Charness et al. 2014; Kilduff et al. 2016); on the other hand, it can be a source of in-group favoritism and reduce unethical behavior in the form of sabotage (Charness et al. 2014). In a rather different study, Benistant and Villeval (2019) divided participants into two groups based on whether 
they preferred paintings by Paul Klee or Wassily Kandinsky. In the contest that was conducted in this minimal group-setting, group membership had no effect on misreporting in a subsequent task, in the sense that those subjects who cheated did so irrespective of the group to which their competitor belonged.

\subsubsection{Rivalry}

In the literature, rivalry has been conceptualized as the relationship between two similar competitors with a history of encounters in contests that led to close outcomes (Kilduff et al. 2010, 2016). While rivalry can increase both motivation and performance (Converse and Reinhard 2016; Kilduff 2014), it can also lead to an extreme "win at all costs" attitude, which is associated with economically irrational behavior, as well as with unethical behavior (Kilduff et al. 2016). In other words, an actor who encounters a rival in a contest is more likely to employ unethical behavior to win the contest than in cases where the same actor encounters non-rivalrous competitors.

Various empirical studies examine the role of rivalry in unethical behavior. For example, Kilduff et al. (2016) found that there is more sabotage, in the form of foul play, in soccer matches between rival clubs. The same authors found that the students of Ohio State University who took part in a laboratory study were more likely to deceive students from a rival university (Michigan University) than students of a non-rivalrous university (Kilduff et al. 2016). In a rather different study, To et al. (2018) demonstrated that rivalry increases physiological arousal, measured by heart rate and skin conductance.

\subsubsection{Heterogeneity}

There is evidence that performance in contests decreases when the contestants are more heterogeneous in their task abilities (Sunde 2009). This heterogeneity has also been shown to affect unethical behavior. Some evidence comes from the study of soccer matches: in two separate studies, Deutscher and colleagues studied the effect of heterogeneity on sabotage. They operationalized "heterogeneity" as the difference in the number of goals scored per team and "sabotage" as the number of yellow and red cards each team received for unsporting behavior (Deutscher et al. 2013; Deutscher and Schneemann 2017). Both studies found that the difference in scored goals was negatively related to sabotage; that is, that sabotage decreased when the difference in performance between the contestants increased. The studies by Frick et al. (2008) and Brown and Chowdhury (2017) yielded similar findings. This implies that actors are less likely to attempt sabotage when it is unlikely to improve their rank or chances of winning. Conversely, sabotage becomes more likely when the contestants are closer in terms of rank or ability.

Contest organizers favor competitors who are homogeneous in terms of ability, because close contests should lead the participants to exert higher effort and increase their performance (Lazear and Rosen 1981). One way contest organizers can achieve homogeneity is to handicap in some way the stronger competitors or determine quotas for disadvantaged competitors (Banerjee et al. 2018; Brown and Chowdhury 
2017). In their field study on horse races, Brown and Chowdhury (2017) found that sabotage is particularly pronounced in handicap contests, not due to handicapping as such, but due to the higher homogeneity among the competitors. On the other hand, Banerjee et al. (2018) found no significant differences in cheating or sabotaging when a disadvantaged group (people from the Scheduled Castes in India) was granted a quota of winner prizes in a contest.

To manipulate task ability in the laboratory, Harbring et al. (2007) divided competing participants into "favorites" and "underdogs." For favorites, the costs of effort were low, while for the underdogs they were high. Their results show that sabotage decreased when the favorites outnumbered the underdogs by two to one: the outnumbered underdogs chose to save costs, as their chances of winning became very low, while the favorites felt superior, as a majority, and less threatened by the underdogs (Harbring et al. 2007). In sum, the literature suggests that unethical behavior in contests increases when participants are on par in terms of ability. It should be noted that homogeneity in terms of task ability can only affect sabotage levels when the contestants are aware of each other's abilities (Gürtler et al. 2013).

\subsubsection{Current rank}

Drawing on a series of scenario studies, Vriend et al. (2016) concluded that unethical behavior is particularly pronounced among individuals who compete for the top ranks rather than for middle or bottom ranks. The presence or absence of a reward does not influence the effect of rank on unethical behavior: the intrinsic value of top ranks triggers unethical behavior regardless of rewards. However, when a top rank is accompanied by a reward and a bottom rank by punishment, contestants who compete for the bottom ranks are more likely to behave unethically and to a higher degree than contestants competing for the top ranks. In other words, imminent punishment appears to carry more weight than a possible reward and competitors are more likely to employ unethical measures to prevent punishment in such circumstances (Kahneman and Tversky 1979; Shechter and Hardisty 2020). The effects of current rank on unethical behavior are comparable to the effects of current rank on performance: contestants who rank either very high or very low expend more effort than the rest (Gill et al. 2018). This indicates that people derive significant utility from ranking first, while ranking at the bottom is associated with extra costs. This also explains why people tend to act more unethically at the top and bottom ends of rankings.

\subsection{Affective state variables}

The empirical findings of studies reviewed to this point suggest that the specific design of a contest has an effect on the contestants' ethical behavior and that this effect depends on individual and situational characteristics. In this section we will look at the psychological mechanisms that mediate the behavioral consequences of contests. As we argued earlier in this review, interpreting competitiveness as an individual's affective state at a given moment allows for a more fine-grained explanation 
of how contests may cause unethical behavior. Previous research suggests that affective responses to external stimuli act as antecedents of behavioral responses (Elfenbein 2007; Oreg et al. 2016). In the following, we will discuss empirical research on state competitiveness and competitive arousal during competition and the role that these factors play in the relationship between contests and unethical behavior (Fig. 1).

\subsubsection{State competitiveness}

In choosing the term "state competitiveness" we allude to the classic distinction between traits and states in psychology (e.g., Korn et al. 1972; Spielberger 1989; Zuckerman 1983). While "traits" refer to relatively stable preferences that vary among different people (Hamaker et al. 2007; Steyer et al. 2015), "states" are transient psychological and physiological conditions that depend not only on one's traits, but also on the situational context. Trait competitiveness can be understood as a general preference for participating in contests that is part of an individual's personality. In contrast, state competitiveness describes a person's competitiveness in a given moment. Trait competitiveness and state competitiveness are distinct but not independent concepts. Trait competitiveness partly determines an individual's state competitiveness in any given moment. This means that someone who scores high in trait competitiveness is expected to display high state competitiveness in contests more often than people who score lower on trait competitiveness (Endler and Kocovski 2001; Steyer et al. 2015). Trait competitiveness can thus be understood as a person's average state competitiveness over time (Hamaker et al. 2007).

In the context of organizations, distinguishing between trait competitiveness and state competitiveness is key to designing contests: while trait competitiveness is a stable personality feature that is not readily altered, state competitiveness can be manipulated-for instance, by changing environmental factors or adjusting contest attributes. Consequently, state competitiveness allows managers to control their employees' behavior in contests.

In the literature, trait competitiveness and state competitiveness are usually discussed separately. Note that while trait competitiveness is an established concept and term, only few papers refer explicitly to "state competitiveness" (cf. Bachman et al. 1997; Veldhuizen Van Zanten et al. 2002). The terms researchers use to refer to related, at least partly overlapping, concepts include "the desire to win" (Malhotra 2010, p. 139) and "performance orientation" (Kilduff et al. 2016, p. 1513). Just like state competitiveness, these concepts refer to transient internal states that are induced by competition and directly linked to the contestants' behavior. Importantly, only few authors discuss the "trait" and "state" versions of competitiveness in tandem (Bachman et al. 1997; Hartmann and Schreck 2018; Malhotra 2010; Veldhuizen Van Zanten et al. 2002).

Social comparison theory can help explain the experience of state competitiveness (Festinger 1954). The theory posits that individuals are constantly making selfevaluations by comparing themselves with similar others. In line with this theory, Garcia et al. (2013) developed a model of competition based on social comparison. Their model introduces the concept "comparison concerns," which the authors 
loosely define as the "desire to achieve or maintain a superior relative position" (Garcia et al. 2013, p. 635). The authors claim that this desire is dependent on the situation and therefore subject to changes. This situational dependency is the unifying feature of all the concepts we have grouped together under the umbrella term "state competitiveness." For example, Malhotra (2010) describes the "desire to win" as a (momentary) willingness to maximize relative payoffs, even at personal cost. Similarly, Kilduff et al. (2016) describe the motivation to win as focusing on one's current rank and on the final outcome of winning in contests, even at the expense of ethical conduct. Another concept that fits this category is "performance orientation," which refers to aiming to outperform others in a particular situation (Kilduff et al. 2016; Murayama and Elliot 2012). The concepts that we subsume under state competitiveness have been measured with one (Bachman et al. 1997; Malhotra 2010) or four self-report items (Kilduff et al. 2016; see Table 3 in the "Appendix" for an overview of the instruments used to assess state competitiveness). However, as "state competitiveness" is not yet established as a unifying construct, there is no widely used and validated instrument for assessing it as yet.

So far, researchers have not examined whether state competitiveness mediates the effect of contest attributes on unethical behavior. However, there is indirect evidence that this may be the case. For example, performance orientation (i.e., state competitiveness) has been shown to mediate the effect of rivalry (a situational variable) on unethical behavior (Kilduff et al. 2016). Other research demonstrates that the desire to win (i.e., state competitiveness) mediates the effect of group size (a contest attribute) on excessive bidding behavior (Malhotra 2010). However, there is no direct empirical evidence that state competitiveness or any related concept mediates the effect of competition on unethical behavior.

\subsubsection{Competitive arousal}

Arousal is a physiological state of alertness, involving the activation of various neural systems (Pfaff et al. 2008; Pribram and Mcguinness 1975). The activation of these systems is related to sensory alertness, mobility, and readiness to respond (Pribram and Mcguinness 1975). Arousal also describes the intensity of an emotion (Posner et al. 2005) and is thought to determine the vigor and persistence of motivated behavior (Pfaff et al. 2008). As a general state, arousal is thought to be valence-free, in that it merely regulates the intensity of an emotion or a behavior. However, the literature also discusses more specific forms of arousal states, such as sexual arousal, hunger, and fear (Pfaff et al. 2008).

In the same vein, competitive arousal-a form of arousal specific to contests-is thought to play a crucial role in competition (Ku et al. 2005, p. 89; Nichols 2012). In the economics and psychology literatures, where the term is mainly used, "competitive arousal" has yet to be consistently defined. Rauch et al. (1999) conceptualize competitive arousal as a pleasant emotion, much like joy, that may be experienced in the context of athletic success-for example, upon scoring an important goal in an ice hockey match. Ku et al. (2005) and Malhotra (2010), on the other hand, describe it as an adrenaline-laden emotional state that can arise in the course of competing. Neither of these studies comments on the valence (i.e., positive/ 
negative) of the emotions that competitive arousal, as they conceptualize it, produces, but specify that it causes irrational and potentially costly behavior, which has negative connotations. ${ }^{5}$

Several studies that measured arousal during contests by assessing changes in blood pressure, levels of skin conductance, or heart-rate variability provide evidence that a person's response to competition involves physiological reactions. Veldhuizen Van Zanten et al. (2002) conducted a study in which participants played a carracing game either alone or against a competitor. The authors' data show that when the participants competed against someone else, their heart rate and blood pressure increased, which indicates heightened arousal. In the rather different setting of an auction, Adam et al. (2015) used continuous physiological measures (i.e., heart rate and skin conductance) as well as short psychometric scales (i.e., questionnaires) to quantify the arousal levels of competing bidders. Their data show that arousal is heightened during a contest, particularly when time pressure is high. The authors also demonstrated that competitors need to be real humans (as opposed to computer opponents) for competition to have an effect on arousal. However, increased heartrate levels and blood pressure during contests may also indicate that subjects experience stress (see Buckert et al. 2017), which reveals that the neurobiological manifestations of competitive arousal are not clear.

It has been argued that, in a broader sense, arousal is associated with motivated behavior of any kind and determines the vigor and persistence of a behavior (Pfaff et al. 2008, p. 15). Whether arousal leads to unethical behavior, however, remains unclear. Ariely and Loewenstein (2006) found that a rather specific type of arousal, sexual arousal, leads men to take "heat-of-the-moment" decisions of dubious morality, such as encouraging a date to drink to increase their chance of having sex with her. With regard to contests, while the studies we review in this section show that competition is related to arousal, they provide no evidence that arousal mediates the effect of competition on unethical behavior. It is conceivable that, as arousal rises and increases vigor and persistence, unethical means to achieving a goal become more acceptable to contestants. However, there is a clear lack of research specifically on competitive arousal and how it may affect unethical behavior.

One reason for the lack of research on competitive arousal and unethical behavior is that measuring competitive arousal is difficult in practical terms. To date, Nichols (2012) has made the most extensive effort to develop an instrument for assessing competitive arousal. The 10-item instrument that Nichols (2012) developed is superior to the single-item instrument that $\mathrm{Ku}$ et al. (2005) used to assess competitive arousal; however, it fails to reflect the physiological dimension of competitive arousal (Pribram and Mcguinness 1975). Instead, the author focuses on specific types of thoughts, feelings, and beliefs. This shortcoming is indicative of the lack

\footnotetext{
$5 \mathrm{Ku}$ et al. (2005) studied excessive bidding in live and online auctions and in the laboratory, in the context of competition between two similar contestants with a history of competitional encounters. The authors find that competitive arousal causes overbidding and is fueled by factors such as time pressure or rivalry (between two similar contestants with a history of encounters in previous contests; Ku et al. 2005).
} 
of consensus on how the relatively new concept of competitive arousal should be defined.

To sum up, our review of the literature on affective states during contests has made clear that research has yet to establish a causal link between affective-statesvariables and unethical behavior. However, the evidence we have discussed indicates that the presence of a contest setting does have an effect on state competitiveness and arousal.

\section{Discussion and research implications}

\subsection{Summary of findings}

Contests are ubiquitous in modern business contexts: the best employees are promoted while rankings offer a straightforward way of determining who the most productive workers are. One drawback of such contests is that they tend to provide incentives to get ahead by cheating and sabotaging other contestants. To tackle unethical behavior in contests efficiently, it is necessary to understand exactly which variables drive this undesirable behavior. To that end, we devised a systematic approach to consulting the varied literature on unethical behavior in contests.

More specifically, we compiled a review of empirical research on illegitimate ways of improving one's rank in contests among employees and developed a framework for organizing the respective studies meaningfully. In the course of our review, we identified and discussed a number of variables that may influence state competitiveness, competitive arousal, and, ultimately, unethical behavior. We identified three clusters of determinants: contest attributes, personal attributes, and situational attributes. We additionally highlighted research on the specific affective statesnamely, competitive arousal and state competitiveness - that help explain how contests can lead to unethical behavior.

Most of the variables we have included in our framework have not been researched extensively: many were studied on a single occasion, while with regard to other variables the evidence is mixed and does not allow for clear conclusions (see Table 2 for an overview). The contest attribute prize spread constitutes an exception to this pattern. Six of the seven empirical studies that examine this attribute indicate that a larger prize spread is associated with a higher incidence of unethical behavior (e.g., Conrads et al. 2014). This points to the importance of setting the different prizes for winners and (where applicable) losers wisely. A more subtle way in which competition affects unethical behavior is by means of framing: two studies provide evidence that simply calling sabotage by its name during a contest or framing the prizes in terms of gains rather than losses can reduce sabotage (Harbring and Irlenbusch 2011; Pettit et al. 2016). On the other hand, research indicates that how much the prizes are worth in total (Harbring and Irlenbusch 2011) or how many individuals participate in the contest (Harbring and Irlenbusch 2008) does not affect unethical behavior.

We identified and reviewed a range of personal attributes that may further qualify the relationship between competition and unethical behavior. The review has shown 
that people with certain characteristics are more likely to act unethically in contests. For example, highly competitive people who score high on trait competitiveness, and on ego trait competitiveness in particular, have a higher propensity for unethical behavior in contests (Jelinek and Ahearne 2010; Mudrack et al. 2012; Terpstra et al. 1993). In contrast to ego trait competitiveness, task trait competitiveness has been associated with predominantly ethical intent (Mudrack et al. 2012). Another attribute that has been widely studied in the context of competition is gender: in behavioral experiments, male participants were more inclined than female participants to cheating or sabotaging in contests (e.g., Dato and Nieken 2014, 2020). Not being good at the task at hand is another attribute that increases the likelihood of unethical behavior according to the reviewed literature (Balafoutas et al. 2012; Deutscher et al. 2013; Schwieren and Weichselbaumer 2010). In sum, the literature shows that being good at the task at hand, being male, and being highly competitive are three attributes associated with unethical behavior aimed at getting ahead in a contest.

The third cluster of determinants we identified comprises situational attributes that can decrease or increase the likelihood of unethical behavior in organizational contests. For example, perceiving the organizational climate as competitive or believing that it is not possible to win the contest in an ethical manner makes people more likely to cheat (Hochstein et al. 2017; Poujol et al. 2016). A few studies also find that when contestants are fairly equal in terms of abilities or, more generally, of chances of winning, it is more likely that some will engage in unethical behavior (e.g., Brown and Chowdhury 2017; Deutscher and Schneemann 2017). The effects of other situational attributes have been considered in experimental studies but mostly not replicated. These studies show that when employees compete with an old rival or when they compete for one of the top ranks, they are more likely to sabotage their competitors (Kilduff et al. 2016; Vriend et al. 2016).

A further question we considered is whether unethical behavior occurs more often when the competitors share attributes with each other-in other words, when they regard each other as a member of the same group. The evidence in this case is rather ambiguous. While Benistant and Villeval (2019) found that sharing a group has no effect on unethical behavior, Charness et al. (2014) found that being in the same group as one's competitors leads to less sabotage but more cheating. Compared to contest attributes or personal attributes, the effects of situational attributes on unethical behavior in contests have been studied to a lesser extent. However, the effect of heterogeneity has been replicated a couple of times: unethical behavior appears to be more prevalent when the performance levels of competing employees are similar (e.g., Deutscher et al. 2013).

The literature on competition includes various concepts that describe people's affective state while they are competing. However, to the best of our knowledge, no studies discuss these concepts as a distinct group of factors that influence the effects of competition on ethical behavior. We argue that, in the context of organizations, considering the factors that shape the affective state of employees during contests is crucial to understanding how competition relates to unethical behavior. Unfortunately, the literature on the relation between affective state during contests and unethical behavior is scarce. As an exception, Kilduff et al. (2016) demonstrate that competing against a fierce rival fosters unethical behavior, because the actor focuses 


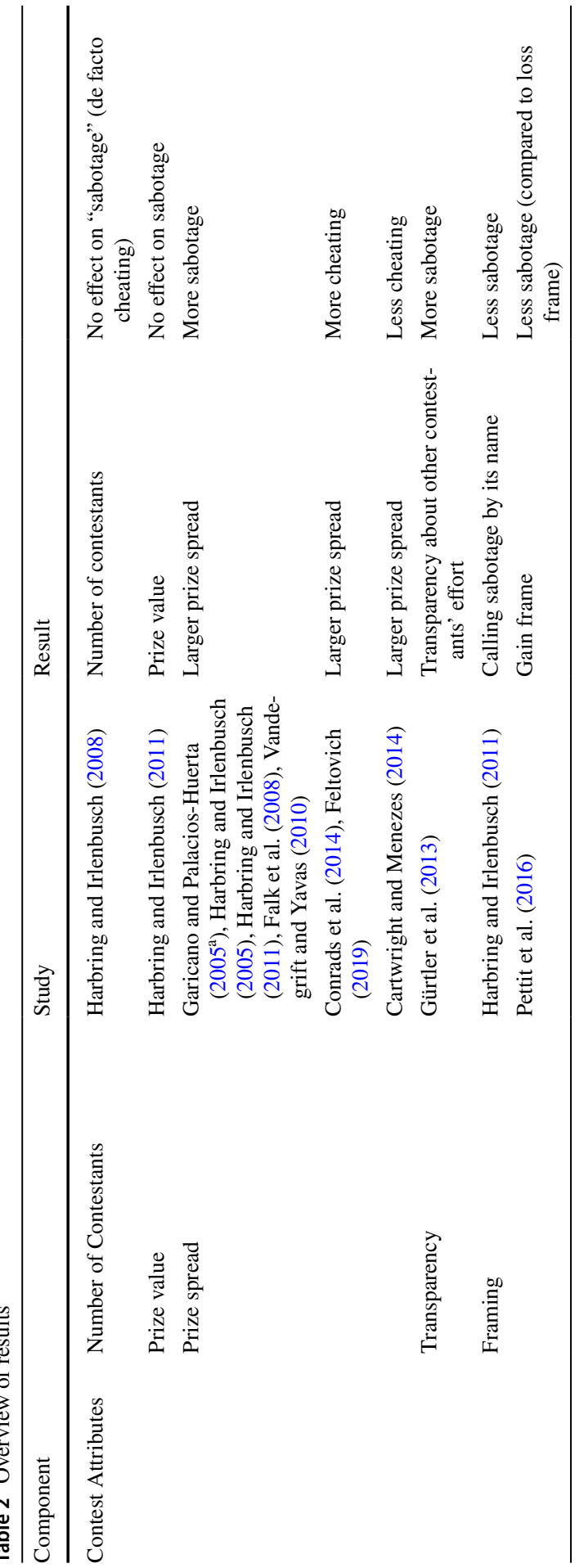




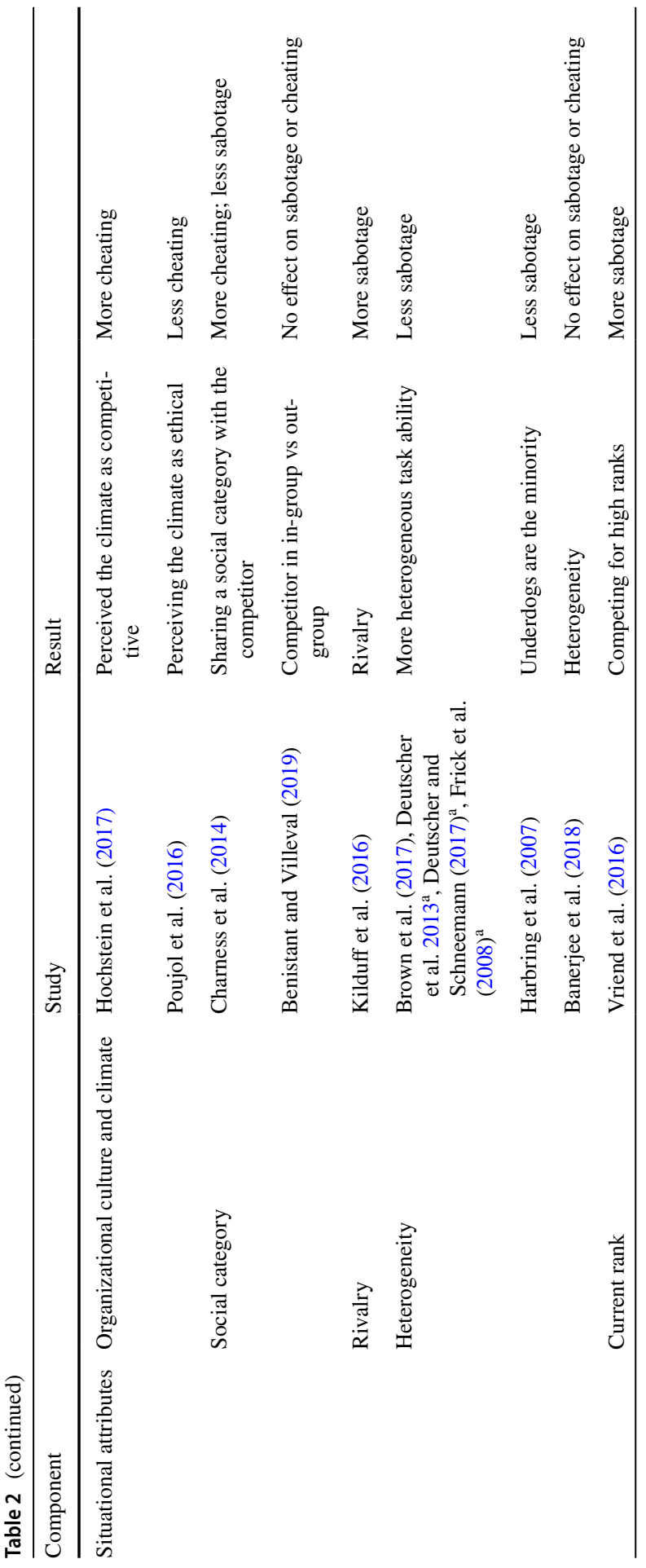




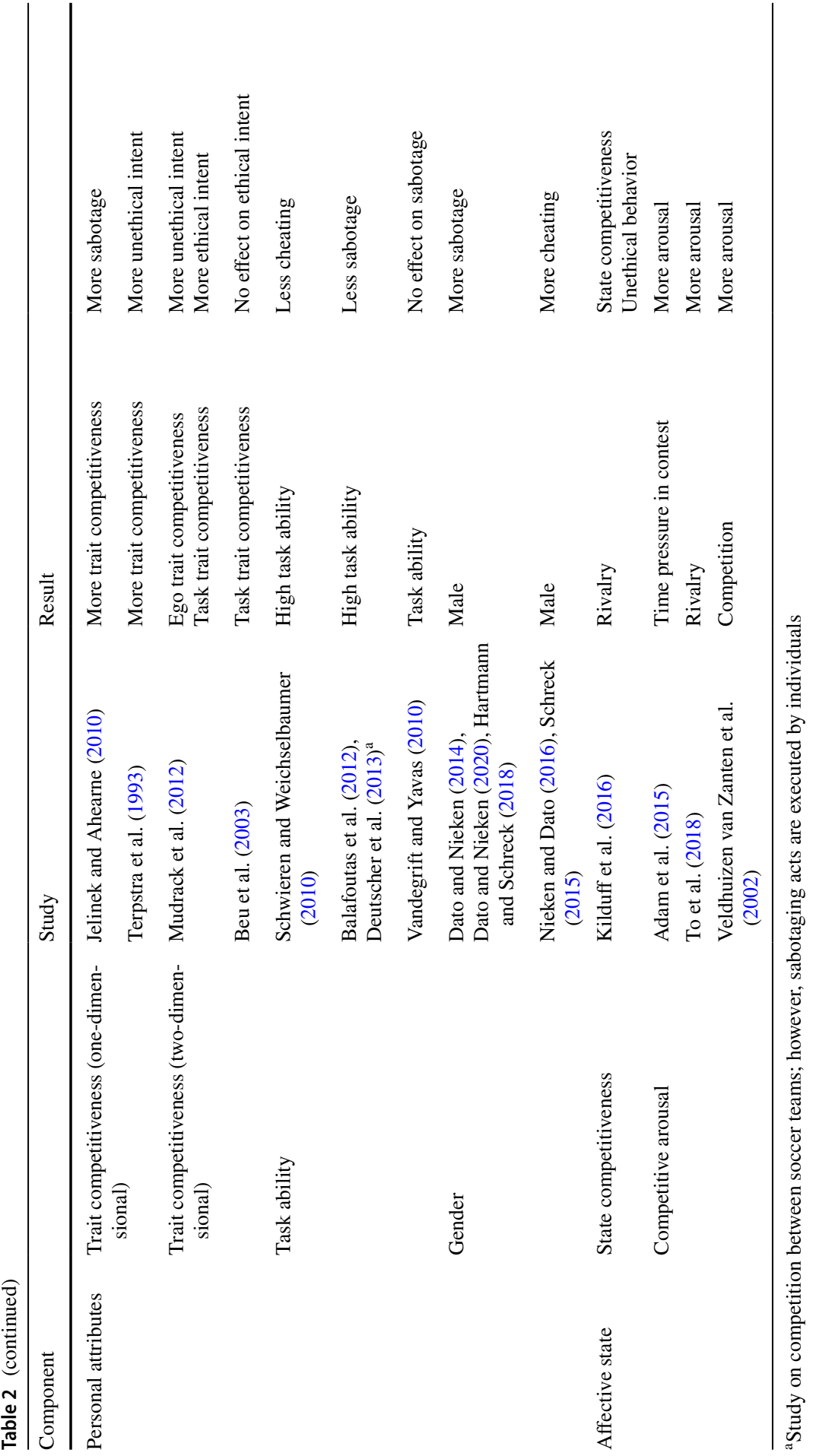


solely on winning. This indicates that the actor is in a state of ego competitiveness and, as a result, fails to reflect critically on how to win in an ethical manner. Other research indicates that competition is associated with increased arousal levels, particularly under time pressure and when there is a fierce rival among the contestants (Adam et al. 2015; To et al. 2018; Veldhuizen Van Zanten et al. 2002). However, more research is needed to substantiate how arousal influences the effect of competition on unethical behavior.

\subsection{Directions for future research}

The framework we have developed for organizing our review of the literature, albeit simple, is demonstrably useful to anyone looking for a systematic overview of relevant research. However, our main objective is to provide a practical tool that will help researchers and practitioners alike gain a better understanding of the factors and conditions that are conducive to unintended and undesirable behavior among competing employees. Admittedly, ethical behavior is not the only concern that preoccupies the managers who organize contests. The primary purpose of such contests is to increase effort among employees (Devaro 2006). As our review indicates, an unintended side effect of contests is unethical behavior. With that in mind, an evident research question is: how should managers design a contest so as to reduce its negative effects on behavior but maintain its positive effects on effort? The answer to this question lies, in our view, in the variables that affect productive effort and performance. When we compare the effects of these variables, on the basis of the reviewed studies, it becomes apparent that many of these variables are associated with both higher performance and a higher degree of unethical behavior. For example, several studies have found that larger prize spreads or competing with a rival increases both effort and the extent of sabotage (Harbring and Irlenbusch 2011; Kilduff 2014; Kilduff et al. 2016). These findings highlight the need to study the outcomes of performance in conjunction with ethical behavior. In order to put into perspective the beneficial effects of competition on performance, it is necessary to examine how they relate to the harmful effects that competition may have on ethical behavior. In this final subsection, we identify some directions for future research on this objective. The section is organized according to our framework's four main determinants: contest design, personal attributes, situational attributes, and affective state.

\subsubsection{Contest attributes}

Contest attributes are, in our view, the parameters that contest organizers can adjust to control unethical behavior. For that reason, we argue that they merit further research. Our review provides certain insights into which contest attributes may have intended and unintended effects. Specifically, as we pointed out earlier, the evidence that prize spread increases both effort and unethical behavior at the same time has been replicated (Conrads et al. 2014; Harbring and Irlenbusch 2011). Similarly, there is evidence that framing contest outcomes in terms of loss rather than gain is associated not only with greater effort (Hossain and List 2012) but also with more unethical 
behavior (Pettit et al. 2016). This suggests that when the organizers of a contest decide on the prize spread or on whether to frame the outcome as a "gain" or "loss," they trade off increases in employee effort against increases in unethical behavior.

Precisely because it is important for managers to take these decisions knowingly, future research needs to focus more on contest attributes that can help managers regulate unethical behavior without compromising effort. The study by Gürtler et al. (2013) appears to be a promising starting point, as the authors were able to increase a contestant's effort and reduce the risk of that contestant sabotaging others. More specifically, sabotage was reduced when contestants had no information about a competitor's performance. This finding is worth trying to replicate in future studies. Additionally, it is worth exploring the boundary conditions of deciding whether contestants should or should not be aware of their competitors' relative or absolute performance; that is, of determining the degree of transparency. In the same context, it is also worth investigating whether such decisions affect cheating as they appear to affect sabotage. From an economic perspective, it makes relatively more sense for a contestant to cheat than to sabotage in the absence of information on his or her competitors' performance. While sabotage can only affect a contestant's rank if the sabotaged competitor happens to rank higher, cheating can improve a contestant's rank either way (Konrad 2000).

Some of the studies we reviewed suggest that increasing the prize value and reducing the number of contestants may increase effort without affecting unethical behavior (Harbring and Irlenbusch 2008, 2011). However, more research is needed to substantiate these findings. From a practical perspective, the number of contestants is a particularly interesting parameter because contest designers can adjust it rather easily.

In contrast to the effects of contest attributes on effort, which have been extensively researched (Dechenaux et al. 2015), many parameters have yet to be studied with respect to their effects on unethical behavior. For example, there is hardly any research on whether the nature of the task that a contest involves affects unethical behavior: do contestants behave more unethically when they compete on a single more complex or in other ways challenging task than on several simpler, smaller ones?

Another factor that remains underexplored is whether being acquainted with one's competitors decreases unethical behavior. It seems reasonable to believe that friends play fairer with each other than with strangers. In other words, it seems plausible that ethical behavior increases when the contestants know (and like) each other. Previous research suggests that contestants who belong to the same social group are less likely to sabotage but are more likely to cheat a competitor (Charness et al. 2014). Future research could investigate whether the degree of familiarity with a competitor has similar effects. In the same vein, it would be interesting to study whether liking a competitor as a person plays a role in ethical behavior - a situational attribute. Naturally, to draw a complete picture, these effects, if any, would need to be evaluated in light of potential performance effects. From a practical perspective, acquaintance is a contest parameter that can only be adjusted in one direction; that is, the contest organizers can ensure that contestants know each other. However, it would be less feasible to prevent contestants who are already acquainted from participating in the same contest. 


\subsubsection{Personal attributes}

Our review indicates that men sabotage competitors more often than women do. Whether the same applies to cheating, we do not know, as there is a distinct lack of research on how gender affects cheating in contests. In contrast to cheating, sabotage is directed at specific victims and therefore contains an element of aggressiveness. Aggressive behavior is generally more common among men than among women (Archer 2004), so the association between male gender and inclination to sabotage seems plausible. Future research could investigate whether gender influences personal preferences for different kinds of unethical behavior; specifically, whether cheating might be women's preferred illegitimate way of gaining an advantage over competitors.

Another personal attribute associated with unethical behavior in contests is trait competitiveness (e.g., Jelinek and Ahearne 2010). However, when we differentiate between ego trait competitiveness and task trait competitiveness, it appears that only ego competitiveness causes unethical behavior. With regard to task trait competitiveness, the picture looks less clear, as one study finds that it actually increases ethical behavior while another study finds that it has no effect on ethical behavior (Beu et al. 2003; Mudrack et al. 2012). Which is the case can only be clarified through further research.

One characteristic that has not received much attention in the literature on competition is achievement motivation (Elliot 1999). The studies that do discuss achievement motivation differentiate between two dimensions. In that respect, achievement motivation share certain characteristics with two-dimensional trait competitiveness: While contestants who pursue performance goals focus on demonstrating greater competence than their competitors, contestants who pursue mastery goals focus on demonstrating greater competence relative to their own previous performance. Van Yperen et al. (2011) find that there is a stronger association between cheating and performance goals than with mastery goals. Similarly, unethical intent is more closely associated with ego trait competitiveness than with task trait competitiveness (Mudrack et al. 2012). The literature on achievement motivation draws a second distinction, in addition to the dichotomy between performance and mastery: "approach orientation" and "avoidance orientation" (Elliot 1999). Murayama and Elliot (2012) argue that competition creates both "approach goals" and "avoidance goals," which have opposite effects on task performance: while approach goals appear to increase performance, avoidance goals appear to decrease it. So far, there is no research on how each orientation affects unethical behavior. Whether contestants with an approach orientation are less prone to unethical behavior and whether contestants who pursue avoidance goals employ unethical behavior to compensate for their generally lower performance (Murayama and Elliot 2012) remain open questions. Research that aims to answer these questions could yield valuable insights into the psychological underpinnings of unethical behavior in contests.

\subsubsection{Situational attributes}

The studies we reviewed suggest that some situational attributes lead contestants to exert greater effort but at the same time increase unethical behavior. Specifically, 
contestants are more likely to increase their effort and also to engage in sabotage when competing with a rival (Kilduff 2014; Kilduff et al. 2016) or for a top rank (Gill et al. 2018; Vriend et al. 2016). An attribute that has not been researched so far is the choice of entering or avoiding a contest. Some research designs compare conditions in which subjects are placed in a contest with conditions in which subjects can choose to participate in a contest (Niederle and Vesterlund 2007). An interesting avenue for future research is studying what effects the presence or absence of choice to enter a contest may have on unethical behavior. For example, it may be the case that employees cheat more when the contest is imposed onto them by a supervisor than when they participate of their own accord.

\subsubsection{Two-dimensional conceptualization of state competitiveness}

In our review we discussed two-dimensional conceptualizations of trait competitiveness: ego trait competitiveness and task trait competitiveness. Here we propose that future research should make a corresponding distinction in the case of state competitiveness between the following two dimensions: ego state competitiveness and task state competitiveness. We believe that this distinction is necessary because it helps explain under which circumstances a contest increases effort without simultaneously increasing unethical behavior.

"Task state competitiveness" refers to an agent's momentary, situationally dependent focus on personal development in a given contest, i.e., on the degree to which the agent perceives the contest as an opportunity to improve his or her mastery of the task at hand. In contrast, when "ego state competitiveness" is the dominant motive in a contest, the agent's focus lies on his or her performance relative to that of competitors. In the latter case, outperforming others and winning the contest becomes a goal in itself, instead of indicating the extent to which the agent has mastered the task. In contrast to trait competitiveness, state competitiveness is situationally contingent, i.e., the specific design of a contest may determine which motive becomes dominant-task competitiveness or ego competitiveness.

We are not the first to propose this idea. In her early work on human cooperation and competition, Mead (1961, p. 17) acknowledged that different situations influence how people perceive things and lead them to focus on either achieving their goals (i.e., task state competitiveness) or on beating their competitors (i.e., ego state competitiveness). More recently, Hartmann and Schreck (2018) distinguished between two dimensions of competitiveness that they refer to as "task focus" and "rivalry focus," arguing that different forms of competition affect the relative importance and salience of both dimensions, which in turn affect unethical behavior. Other research refers to two-dimensional state competitiveness more implicitly. For instance, Malhotra (2010) measured the "real-time motivations of online auction bidders" in terms of "competitive motivation" (i.e., task state competitiveness) versus a "desire to win" (i.e., ego state competitiveness).

Conceiving state competitiveness as a two-dimensional rather than a one-dimensional concept may be more useful for the purpose of reducing unethical behavior because it allows researchers to disentangle distinct and potentially contradictory effects. For example, one advantage of the two-dimensional concept of trait 
competitiveness is that it captures the contrary effects that these dimensions have on unethical behavior. While ego trait competitiveness leads to unethical behavior (Mudrack et al. 2012), task trait competitiveness is unrelated or even negatively related to unethical behavior (Beu et al. 2003; Mudrack et al. 2012). We would expect the same to apply to the cases of ego state competitiveness and task state competitiveness. Specifically, we expect that ego state competitiveness is associated with unethical behavior, because cheating and sabotage help the actor win a specific contest. In contrast, we expect task state competitiveness to be unrelated to unethical behavior because cheating and sabotage do not help an actor improve his or her mastery of a given task. There is some empirical support for this prediction: Sage and Kavussanu (2007) manipulated the task involvement and ego involvement of subjects who participated in a game of table soccer and measured the players' moral behavior. The authors manipulated each type of involvement by providing relevant cues (such as stressing winning versus learning) in the description of the task, which the subjects read prior to the contest. The results indicate that ego-involved individuals display more antisocial behavior whereas task-involved individuals make more prosocial choices.

In order to gain an understanding of the antecedents and consequences of ego state competitiveness and task state competitiveness, future research needs to develop an appropriate instrument for measuring two-dimensional state competitiveness. Such an instrument does not yet exist but would be a prerequisite for empirically testing the effects of the two dimensions of state competitiveness on unethical behavior. It is possible that the imprecise terminology that is used in the literature on competition has impeded the development of appropriate measurement instruments.

Lastly, the two-dimensional concept of state competitiveness may provide contest designers with another way of minimizing unethical behavior without affecting effort. Specifically, and on the basis of the research we have reviewed, contest designers would need to foster task state competitiveness and reduce ego state competitiveness. Future research could explore these options in depth.

In the course of the review, we repeatedly claimed that managers employ contests in order to stimulate employee performance (Devaro 2006). It is not self-evident, however, that inducing employees to exert maximum effort is a generally good strategy (Kohn 1992). There are many factors to take into account when evaluating the overall utility of competition. For example, what are the psychological costs of stress during contests and what are the effects of losing (Brandts et al. 2009)? Do the benefits of competition outweigh the diminishing effects on employee cooperation (Chambers and Baker 2020)? These are questions related to the normative foundations of contests in organizations - their discussion, however, is beyond the scope of this paper.

\section{Conclusion}

In this study, we reviewed the empirical literature on contests and unethical behavior in organizations with the aid of a framework we developed for organizing the respective works systematically. This literature suggests that unethical behavior is 
largely determined by three clusters of factors; namely contest attributes, personal attributes, and situational attributes. Several works we have included in our review have replicated multiple times the findings on the variables that correspond to these factors-and it is precisely these factors that organizations should consider when designing contests. For example, a large prize spread is likely to increase the occurrence of unethical behavior. Also, a heterogeneous group of contestants is likely to exhibit less unethical behavior than a more homogeneous group. With regard to personal attributes, low ability to complete the task at hand, male gender, and a high degree of competitiveness all increase the likelihood of unethical behavior. For practitioners, situational attributes and personal attributes are possibly of less interest, because it is not easy to manipulate either category. On the basis of the reviewed literature, we also argued that in order to study empirically the affective components of competitiveness, such as competitive arousal and state competitiveness, and their role in unethical behavior, it is necessary to begin by developing valid measuring instruments.

The simple framework we developed helps eliminate inconsistencies in terminology and resolve the ambiguous usage of terms such as "competition" or "competitiveness." Moreover, this framework can prove useful in developing specific and testable research models and hypotheses on which trade-offs between effort and unethical behavior are most advantageous and on how effectively different attributes or combinations of attributes may regulate unethical behavior without compromising effort.

Acknowledgements We gratefully acknowledge the feedback of two anonymous reviewers as well as various other reviewers' input to earlier versions of the manuscript.

Authors' contributions PS had the idea for the article. SP performed the literature search and data analysis. SP and PS wrote the paper.

Funding Open Access funding enabled and organized by Projekt DEAL.

\section{Compliance with ethical standards}

Conflict of interest The authors declare no conflict of interest.

Open Access This article is licensed under a Creative Commons Attribution 4.0 International License, which permits use, sharing, adaptation, distribution and reproduction in any medium or format, as long as you give appropriate credit to the original author(s) and the source, provide a link to the Creative Commons licence, and indicate if changes were made. The images or other third party material in this article are included in the article's Creative Commons licence, unless indicated otherwise in a credit line to the material. If material is not included in the article's Creative Commons licence and your intended use is not permitted by statutory regulation or exceeds the permitted use, you will need to obtain permission directly from the copyright holder. To view a copy of this licence, visit http://creativecommons.org/licen ses/by/4.0/.

\section{Appendix}

See Table 3. 


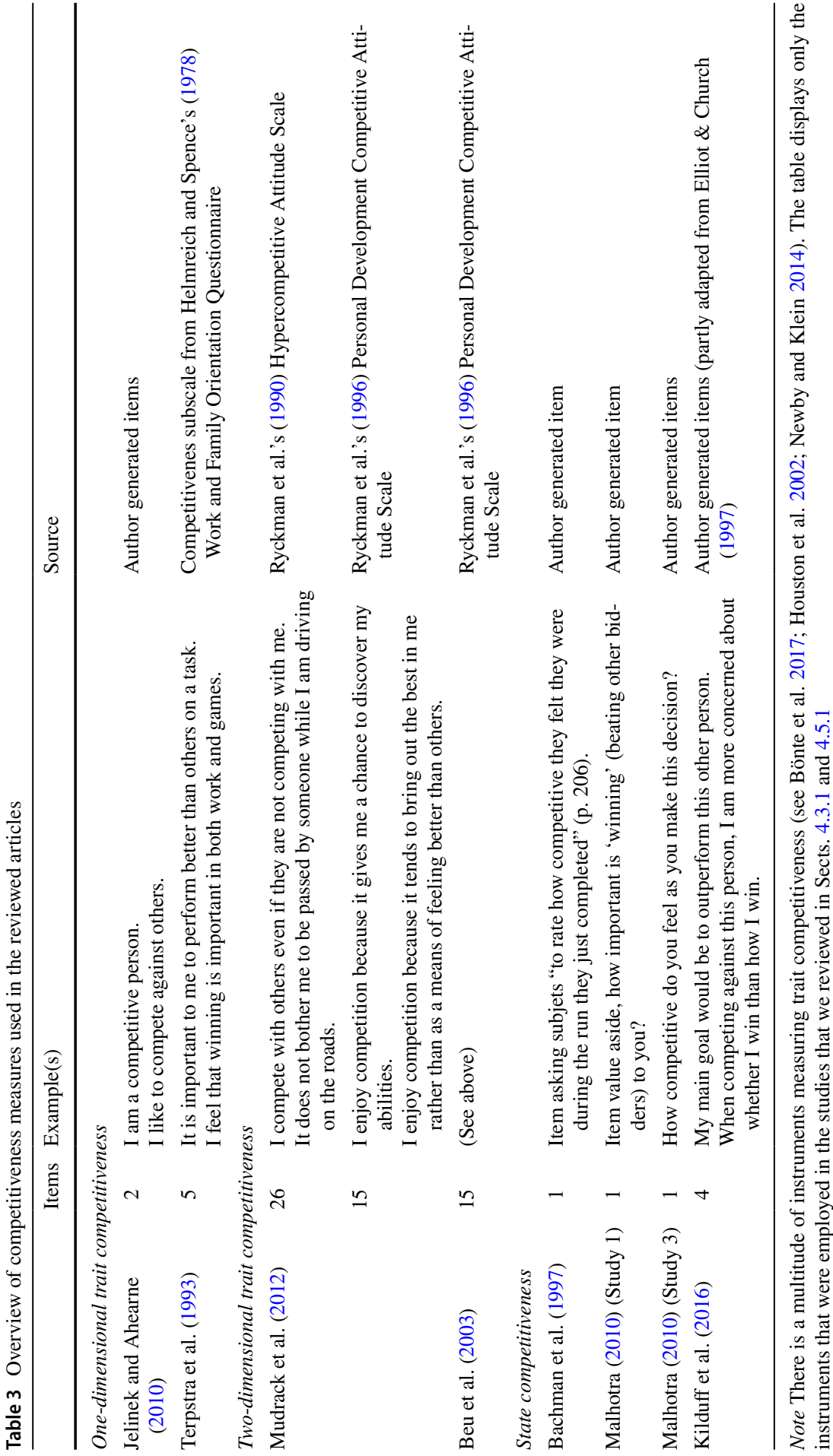




\section{References}

Adam MT, Krämer J, Müller MB (2015) Auction fever! How time pressure and social competition affect bidders' arousal and bids in retail auctions. J Retail 91(3):468-485

Archer J (2004) Sex differences in aggression in real-world settings: a meta-analytic review. Rev Gen Psychol 8(4):291-322

Ariely D, Loewenstein G (2006) The heat of the moment: the effect of sexual arousal on sexual decision making. J Behav Decis Mak 19(2):87-98

Arnaud A, Schminke M (2012) The ethical climate and context of organizations: a comprehensive model. Organ Sci 23(6):1767-1780

Arora-Jonsson S, Brunsson N, Hasse R (2020) Where does competition come from? The role of organization. Organ Theor 1(1):1-24

Aydogan G, Jobst A, D'ardenne K, Müller N, Kocher MG (2017) The detrimental effects of oxytocininduced conformity on dishonesty in competition. Psychol Sci 28(6):751-759

Azmat G, Iriberri N (2010) The importance of relative performance feedback information: evidence from a natural experiment using high school students. J Publ Econ 94(7):435-452

Bachman AD, Brewer BW, Petitpas AJ (1997) Situation specificity of cognitions during running: replication and extension. J Appl Sport Psychol 9(2):204-211

Balafoutas L, Lindner F, Sutter M (2012) Sabotage in tournaments: evidence from a natural experiment. Kyklos 65(4):425-441

Balliet D, Mulder LB, Van Lange PA (2011) Reward, punishment, and cooperation: a meta-analysis. Psychol Bull 137(4):594

Banerjee R, Gupta ND, Villeval MC (2018) The spillover effects of affirmative action on competitiveness and unethical behavior. Europ Econ Rev 101:567-604

Belot M, Schröder M (2013) Sloppy work, lies and theft: a novel experimental design to study counterproductive behaviour. J Econ Behav Organ 93:233-238

Benistant J, Villeval MC (2019) Unethical behavior and group identity in contests. J Econ Psychol 72:128-155

Berentsen A, Lengwiler Y (2004) Fraudulent accounting and other doping games. J Inst Theor Econ 160(3):402-415

Beu DS, Buckley MR, Harvey MG (2003) Ethical decision-making: a multidimensional construct. Bus Ethics Eur Rev 12(1):88-107

Blanes I, Vidal J, Nossol M (2011) Tournaments without prizes: evidence from personnel records. Manag Sci 57(10):1721-1736

Bönte W, Lombardo S, Urbing D (2017) Economics meets psychology: experimental and self-reported measures of individual competitiveness. Pers Individ Dif 116:179-185

Bracha A, Fershtman C (2013) Competitive incentives: working harder or working smarter? Manage Sci 59(4):771-781

Brandts J, Riedl A, Van Winden F (2009) Competitive rivalry, social disposition, and subjective wellbeing: an experiment. J Public Econ 93(11):1158-1167

Brown A, Chowdhury SM (2017) The hidden perils of affirmative action: sabotage in handicap contests. J Econ Behav Organ 133:273-284

Brown SP, Cron WL, Slocum JW (1998) Effects of trait competitiveness and perceived intraorganizational competition on salesperson goal setting and performance. J Mark 62:88-98

Buckert M, Schwieren C, Kudielka BM, Fiebach CJ (2017) How stressful are economic competitions in the lab? An investigation with physiological measures. J Econ Psychol 62:231-245

Butterfield KD, Treviño LK, Weaver GR (2000) Moral awareness in business organizations: influences of issue-related and social context factors. Hum Relat 53(7):981-1018

Cardinaels E, Chen CX, Yin H (2018) Leveling the playing field: the selection and motivation effects of tournament prize spread information. Account Rev 93(4):127-149

Carpenter J, Matthews PH, Schirm J (2010) Tournaments and office politics: evidence from a real effort experiment. Am Econ Rev 100(1):504-517

Cartwright E, Menezes ML (2014) Cheating to win: dishonesty and the intensity of competition. Econ Letters 122(1):55-58

Chambers CR, Baker WE (2020) Robust systems of cooperation in the presence of rankings: how displaying prosocial contributions can offset the disruptive effects of performance rankings. Organ Sci 31(2):287-307 
Charness G, Masclet D, Villeval MC (2014) The dark side of competition for status. Manag Sci 60(1):38-55

Chen KP (2003) Sabotage in promotion tournaments. J Law Econ Organ 19(1):119-140

Chowdhury SM, Gürtler O (2015) Sabotage in contests: a survey. Public Choice 164(1-2):135-155

Clark WR, Clark LA, Raffo DM, Williams Jr. RI (2020) Extending Fisch and Block's (2018) tips for a systematic review in management and business literature. Manag Rev Q. Advance online publication

Connelly BL, Tihanyi L, Crook TR, Gangloff KA (2014) Tournament theory: thirty years of contests and competitions. J Manage 40(1):16-47

Conrads J, Irlenbusch B, Rilke RM, Schielke A, Walkowitz G (2014) Honesty in tournaments. Econ Lett 123(1):90-93

Converse BA, Reinhard DA (2016) On rivalry and goal pursuit: shared competitive history, legacy concerns, and strategy selection. J Pers Soc Psychol 110(2):191-213

Dato S, Nieken P (2014) Gender differences in competition and sabotage. J Econ Behav Organ 100:64-80

Dato S, Nieken P (2020) Gender differences in sabotage: the role of uncertainty and beliefs. Exper Econ 23:353-391

Dechenaux E, Kovenock D, Sheremeta RM (2015) A survey of experimental research on contests, all-pay auctions and tournaments. Exp Econ 18(4):609-669

Delfgaauw J, Dur R, Sol J, Verbeke W (2013) Tournament incentives in the field: gender differences in the workplace. J Labor Econ 31(2):305-326

Deutsch M (1949) A theory of co-operation and competition. Hum Relat 2(2):129-152

Deutscher C, Schneemann S (2017) The impact of intermediate information on sabotage in tournaments with heterogeneous contestants. Manage Decis Econ 38(2):222-237

Deutscher C, Frick B, Gürtler O, Prinz J (2013) Sabotage in tournaments with heterogeneous contestants: empirical evidence from the soccer pitch. Scand J Econ 115(4):1138-1157

Devaro J (2006) Strategic promotion tournaments and worker performance. Strat Manage J 27:721-740

Dohmen T, Falk A, Fliessbach K, Sunde U, Weber B (2011) Relative versus absolute income, joy of winning, and gender: brain imaging evidence. J Publ Econ 95(3):279-285

Dutcher EG, Balafoutas L, Lindner F, Ryvkin D, Sutter M (2015) Strive to be first or avoid being last: an experiment on relative performance incentives. Game Econ Behav 94:39-56

Edelman B, Larkin I (2014) Social comparisons and deception across workplace hierarchies: field and experimental evidence. Organ Sci 26(1):78-98

Elfenbein HA (2007) Emotion in organizations: a review and theoretical integration. Acad Manag Ann $1(1): 315-386$

Elliot AJ (1999) Approach and avoidance motivation and achievement goals. Educ Psychol 34(3):169-189

Elliot AJ, Church MA (1997) A hierarchical model of approach and avoidance achievement motivation. J Pers Soc Psychol 72(1):218-232

Endler NS, Kocovski NL (2001) State and trait anxiety revisited. J Anxiety Disord 15(3):231-245

Falk A, Fehr E, Huffman D (2008) The power and limits of tournament incentives. Working Paper, University of Bonn. https://www.researchgate.net/publication/228982197_The_Power_and_Limit s_of_Tournament_Incentives. Accessed 11 September 2020

Feltovich N (2019) The interaction between competition and unethical behaviour. Exper Econ 22(1):101-130

Festinger L (1954) A theory of social comparison processes. Hum Relat 7(2):117-140

Fisch C, Block J (2018) Six tips for your (systematic) literature review in business and management research. Manag Rev Q 68:103-106

Fletcher TD, Nusbaum DN (2008) Trait competitiveness as a composite variable: linkages with facets of the big-five. Pers Individ Dif 45(4):312-317

Fliessbach K, Weber B, Trautner P, Dohmen T, Sunde U, Elger CE et al (2007) Social comparison affects reward-related brain activity in the human ventral striatum. Science 318(5854):1305-1308

Franken RE, Brown DJ (1995) Why do people like competition? The motivation for winning, putting forth effort, improving one's performance, performing well, being instrumental, and expressing forceful/aggressive behavior. Pers Individ Dif 19(2):175-184

Frick B, Gürtler O, Prinz J (2008) Anreize in turnieren mit heterogenen teilnehmern-eine empirische untersuchung mit daten aus der fussball-bundesliga. Schmalenbachs Z Betriebswirtsch Forsch 60:385-405

Garcia SM, Tor A (2009) The n-effect more competitors, less competition. Psychol Sci 20(7):871-877 
Garcia SM, Tor A, Schiff TM (2013) The psychology of competition a social comparison perspective. Perspect Psychol Sci 8(6):634-650

Garicano L, Palacios-Huerta I (2005) Sabotage in tournaments: making the beautiful game a bit less beautiful. Working Paper, University of Chicago. https://www.researchgate.net/publication/48429 50_Sabotage_in_Tournaments_Making_the_Beautiful_Game_a_Bit_Less_Beautiful. Accessed 11 September 2020

Gill D (1986) Competitiveness among females and males in physical activity classes. Sex Roles 15(5-6):233-247

Gill D, Kissová Z, Lee J, Prowse V (2018) First-place loving and last-place loathing: how rank in the distribution of performance affects effort provision. Manage Sci 65(2):494-507

Gilpatric SM (2011) Cheating in contests. Econ Inq 49(4):1042-1053

Gneezy U, Rustichini A (2004) Gender and competition at a young age. Am Econ Rev 94(2):377-381

Gneezy U, Niederle M, Rustichini A (2003) Performance in competitive environments: gender differences. Quart J Econ 118(3):1049-1074

Griffin-Pierson S (1990) The competitiveness questionnaire: a measure of two components of competitiveness. Measur Evaluat Counsel Develop 23(3):108-115

Grolleau G, Kocher MG, Sutan A (2016) Cheating and loss aversion: do people cheat more to avoid a loss? Manage Sci 62(12):3428-3438

Grote D (2005) Forced ranking: making performance management work. Harvard Business Review Press, Boston

Gürtler O, Münster J, Nieken P (2013) Information policy in tournaments with sabotage. Scand J Econ 115(3):932-966

Hamaker EL, Nesselroade JR, Molenaar PC (2007) The integrated trait-state model. J Res Pers 41(2):295-315

Hanek KJ, Garcia SM, Tor A (2016) Gender and competitive preferences: the role of competition size. J Appl Psychol 101(8):1122-1133

Hannan RL, Krishnan R, Newman AH (2008) The effects of disseminating relative performance feedback in tournament and individual performance compensation plans. Account Rev 83(4):893-913

Harbring C, Irlenbusch B (2003) An experimental study on tournament design. Lab Econ 10(4):443-464

Harbring C, Irlenbusch B (2005) Incentives in tournaments with endogenous prize selection. J Inst Theor Econ 161:636-663

Harbring C, Irlenbusch B (2008) How many winners are good to have?: on tournaments with sabotage. J Econ Behav Organ 65(3):682-702

Harbring C, Irlenbusch B (2011) Sabotage in tournaments: evidence from a laboratory experiment. Manage Sci 57(4):611-627

Harbring C, Lunser GK (2008) On the competition of asymmetric agents. Ger Econ Rev 9(3):373-395

Harbring C, Irlenbusch B, Kräkel M, Selten R (2007) Sabotage in corporate contests-an experimental analysis. Int J Econ Bus 14(3):367-392

Harmon-Jones E, Gable PA, Price TF (2013) Does negative affect always narrow and positive affect always broaden the mind? Considering the influence of motivational intensity on cognitive scope. Curr Dir Psychol Sci 22(4):301-307

Harris PB, Houston JM (2010) A reliability analysis of the revised competitiveness index. Psychol Rep 106(3):870-874

Hartmann F, Schreck P (2018) Rankings, performance, and sabotage: the moderating effects of target setting. Eur Account Rev 27(2):363-382

Helmreich RL, Spence JT (1978) The work and family orientation questionnaire: an objective instrument to assess components of achievement motivation and attitudes toward family and career. JSAS Cat Sel Doc Psychol 8:35

Hibbard DR, Buhrmester D (2010) Competitiveness, gender, and adjustment among adolescents. Sex Roles 63(5-6):412-424

Hochstein BW, Zahn WJ, Bolander W (2017) Exploring the unintended negative impact of an ethical climate in competitive environments. Mark Lett 28(4):621-635

Hogg MA, Terry DI (2000) Social identity and self-categorization processes in organizational contexts. Acad Manage Rev 25(1):121-140

Horney K (1936) Culture and neurosis. Am Sociol Rev 1(2):221-230

Hossain T, List JA (2012) The behavioralist visits the factory: increasing productivity using simple framing manipulations. Manage Sci 58(12):2151-2167 
Houston JM, Farese DM, La Du TJ (1992) Assessing competitiveness: a validation study of the competitiveness index. Pers Individ Diff 13(10):1153-1156

Houston JM, Mcintire SA, Kinnie J, Terry C (2002) A factorial analysis of scales measuring competitiveness. Educ Psychol Meas 62(2):284-298

Houston JM, Harris PB, Howansky K, Houston SM (2015) Winning at work: trait competitiveness, personality types, and occupational interests. Pers Individ Diff 76:49-51

Jelinek R, Ahearne M (2010) Be careful what you look for: the effect of trait competitiveness and long hours on salesperson deviance and whether meaningfulness of work matters. J Market Theor Pract 18(4):303-321

Johnson DW, Johnson RT (1989) Cooperation and competition: theory and research. Interaction Book Company, Edina

Jones TM (1991) Ethical decision making by individuals in organizations: an issue-contingent model. Acad Manage Rev 16(2):366-395

Joos HC (2019) Influences on managerial perceptions of stakeholder salience: two decades of research in review. Manage Rev Q 69(1):3-37

Kahneman D, Tversky A (1979) Prospect theory-analysis of decision under risk. Econometrica 47(2):263-291

Kern MC, Chugh D (2009) Bounded ethicality: the perils of loss framing. Psychol Sci 20(3):378-384

Kilduff GJ (2014) Driven to win rivalry, motivation, and performance. Soc Psychol Pers Sci 5(8):944-952

Kilduff GJ, Elfenbein HA, Staw BM (2010) The psychology of rivalry: a relationally dependent analysis of competition. Acad Manage J 53(5):943-969

Kilduff GJ, Galinsky AD, Gallo E, Reade J (2016) Whatever it takes to win: rivalry increases unethical behavior. Acad Manage J 59(5):1508-1534

Köbis NC, Verschuere B, Bereby-Meyer Y, Rand D, Shalvi S (2019) Intuitive honesty versus dishonesty: meta-analytic evidence. Perspect Psychol Sci 14(5):778-796

Kohn A (1992) No contest: the case against competition. Houghton Mifflin, New York

Konrad KA (2000) Sabotage in rent-seeking contests. J Law Econ Organ 16(1):155-165

Korn EJ, Ascough JC, Kleemeier RB (1972) The effects of induced anxiety on state-trait measures of anxiety in high, middle, and low trait-anxious individuals. Behav Ther 3(4):547-554

Ku G, Malhotra D, Murnighan JK (2005) Towards a competitive arousal model of decision-making: a study of auction fever in live and internet auctions. Organ Behav Hum Decis Process 96(2):89-103

Kuhnen CM, Tymula A (2012) Feedback, self-esteem, and performance in organizations. Manag Sci 58(1):94-113

Lazear EP (1989) Pay equality and industrial politics. J Polit Econ 97(3):561-580

Lazear EP, Rosen S (1981) Rank-order tournaments as optimum labor contracts. J Polit Econ 89(5):841-864

Lewin K (1935) A dynamic theory of personality. McGraw-Hill, New York

Lewis HB (1944) An experimental study of the role of the ego in work. I. The role of the ego in cooperative work. J Exp Psychol Gen 34(2):113-126

Loe TW, Ferrell L, Mansfield P (2000) A review of empirical studies assessing ethical decision making in business. J Bus Ethics 25(3):185-204

Malhotra D (2010) The desire to win: the effects of competitive arousal on motivation and behavior. Organ Behav Hum Decis Process 111(2):139-146

Malhotra D, Ku G, Murnighan JK (2008) When winning is everything. Harv Bus Rev 86(5):78-86

Martens R (1975) Social psychology and physical activity. Harper \& Row, New York

Mead M (1961) Cooperation and competition among primitive peoples. Beacon, Boston

Messick DM (1999) Alternative logics for decision making in social settings. J Econ Behav Organ 39(1):11-28

Mudrack PE, Bloodgood JM, Turnley WH (2012) Some ethical implications of individual competitiveness. J Bus Ethics 108(3):347-359

Murayama K, Elliot AJ (2012) The competition-performance relation: a meta-analytic review and test of the opposing processes model of competition and performance. Psychol Bull 138(6):1035-1070

Newby JL, Klein RG (2014) Competitiveness reconceptualized: psychometric development of the competitiveness orientation measure as a unified measure of trait competitiveness. Psychol Rec 64(4):879-895

Nicholls JG (1984) Achievement-motivation-conceptions of ability, subjective experience, task choice, and performance. Psychol Rev 91(3):328-346 
Nichols BS (2012) The development, validation, and implications of a measure of consumer competitive arousal (CCAr). J Econ Psychol 33(1):192-205

Niederle M, Vesterlund L (2007) Do women shy away from competition? Do men compete too much? Q J Econ 122(3):1067-1101

Niederle M, Vesterlund L (2011) Gender and competition. Ann Rev Econ 3(1):601-630

Nieken P, Dato S (2016) Compensation and honesty: gender differences in lying. Beiträge zur Jahrestagung des Vereins für Socialpolitik 2016: Demographischer Wandel-Session: Organizational Design, No. A23-V3

Oreg S, Bartunek J, Lee G, Do B (2016) An affect-based model of recipients' responses to organizational change events. Acad Manag Rev 43(1):65-86

Pettit NC, Doyle SP, Lount RB, To C (2016) Cheating to get ahead or to avoid falling behind? The effect of potential negative versus positive status change on unethical behavior. Organ Behav Hum Decis Process 137:172-183

Pfaff D, Ribeiro A, Matthews J, Kow LM (2008) Concepts and mechanisms of generalized central nervous system arousal. Ann New York Acad Sci 1129(1):11-25

Pierce JR, Kilduff GJ, Galinsky AD, Sivanathan N (2013) From glue to gasoline: how competition turns perspective takers unethical. Psychol Sci 24(10):1986-1994

Posner J, Russell JA, Peterson BS (2005) The circumplex model of affect: an integrative approach to affective neuroscience, cognitive development, and psychopathology. Dev Psychopathol 17(3):715-734

Poujol F-J, Harfouche A, Pezet E (2016) Salespeople's unethical behavior during a sales contest: the mediation effect of the perceived ethical climate of the game. Rech Appl Market (English Edition) 31(2):21-39

Preston I, Szymanski S (2003) Cheating in contests. Oxford Rev Econ Pol 19(4):612-624

Pribram KH, Mcguinness D (1975) Arousal, activation, and effort in the control of attention. Psychol Rev 82(2):116-149

Rauch SL, Shin LM, Dougherty DD, Alpert NM, Orr SP, Lasko M et al (1999) Neural activation during sexual and competitive arousal in healthy men. Psychiatr Res Neuroimag 91(1):1-10

Reeves B, Read JL (2013) Total engagement: how games and virtual worlds are changing the way people work and businesses compete. Harvard Business Review Press, Boston

Rigdon ML, D'esterre AP (2015) The effects of competition on the nature of cheating behavior. South Econ J 81(4):1012-1024

Rosenkrantz P, Vogel S, Bee H, Broverman I, Broverman DM (1968) Sex-role stereotypes and self-concepts in college students. J Consult Clin Psychol 32(3):287-295

Ryckman RM, Hammer M, Kaczor LM, Gold JA (1990) Construction of a hypercompetitive attitude scale. J Pers Assess 55(3-4):630-639

Ryckman RM, Thornton B, Butler JC (1994) Personality correlates of the hypercompetitive attitude scale: validity tests of horney's theory of neurosis. J Pers Assess 62(1):84-94

Ryckman RM, Hammer M, Kaczor LM, Gold JA (1996) Construction of a personal development competitive attitude scale. J Pers Assess 66(2):374-385

Ryckman RM, Libby CR, Van Den Borne B, Gold JA, Lindner MA (1997) Values of hypercompetitive and personal development competitive individuals. J Pers Assess 69(2):271-283

Saccardo S, Pietrasz A, Gneezy U (2018) On the size of the gender difference in competitiveness. Manage Sci 64(4):1541-1554

Sage L, Kavussanu M (2007) The effects of goal involvement on moral behavior in an experimentally manipulated competitive setting. J Sport Exerc Psychol 29(2):190-207

Schindler S, Pfattheicher S (2017) The frame of the game: loss-framing increases dishonest behavior. J Exp Soc Psychol 69:172-177

Schreck P (2015) Honesty in managerial reporting: how competition affects the benefits and costs of lying. Crit Perspect Account 27:177-188

Schurr A, Ritov I (2016) Winning a competition predicts dishonest behavior. Proc Natl Acad Sci Unit States Am 113(7):1754-1759

Schwieren C, Weichselbaumer D (2010) Does competition enhance performance or cheating? A laboratory experiment. J Econ Psychol 31(3):241-253

Shechter SM, Hardisty DJ (2020) Preferences for rank in competition: is first-place seeking stronger than last-place aversion? Judg Dec Making 15(2):246-253

Smither RD, Houston JM (1992) The nature of competitiveness: the development and validation of the competitiveness index. Educ Psychol Meas 52(2):407-418 
Spence JT, Helmreich RL (1983) Achievement related motives and behavior. In: Spence JT (ed) Achievement and achievement motives: psychological and sociological dimensions. Freeman, San Francisco, pp 7-74

Spielberger CD (1989) State-trait anxiety inventory: bibliography. Consulting Psychologists Press, Palo Alto

Stanne MB, Johnson DW, Johnson RT (1999) Does competition enhance or inhibit motor performance: a meta-analysis. Psychol Bull 125(1):133-154

Steyer R, Mayer A, Geiser C, Cole D (2015) A theory of states and traits-revised. Annu Rev Clin Psychol 11(1):71-98

Sunde U (2009) Heterogeneity and performance in tournaments: a test for incentive effects using professional tennis data. Appl Econ 41(25):3199-3208

Tafkov ID (2013) Private and public relative performance information under different compensation contracts. Account Rev 88(1):327-350

Tajfel H, Turner JC (1979) An integrative theory of intergroup conflict. In: Austin W, Worchel S (eds) The social psychology of intergroup relations. Brooks/Cole, Pacific Grove, pp 33-48

Tajfel H, Billig MG, Bundy RP, Flament C (1971) Social categorization and intergroup behaviour. Eur J Soc Psychol 1(2):149-178

Tassi F, Schneider BH (1997) Task-oriented versus other-referenced competition: differential implications for children's peer relations. J Appl Soc Psychol 27(17):1557-1580

Terpstra DE, Rozell EJ, Robinson RK (1993) The influence of personality and demographic variables on ethical decisions related to insider trading. J Psychol 127(4):375-389

Thomas O (2018) Two decades of cognitive bias research in entrepreneurship: what do we know and where do we go from here? Manag Rev Q 68(2):107-143

To C, Kilduff GJ, Ordoñez L, Schweitzer ME (2018) Going for it on fourth down: rivalry increases risktaking, physiological arousal, and promotion focus. Acad Manage J 61(4):1281-1306

To C, Kilduff GJ, Rosikiewicz B (2020) When interpersonal competition helps and when it harms: an integration via challenge and threat. Acad Manage Ann 14(2):908-934

Tran A, Zeckhauser R (2012) Rank as an inherent incentive: evidence from a field experiment. J Public Econ 96(9-10):645-650

Treviño LK (1986) Ethical decision making in organizations: a person-situation interactionist model. Acad Manage Rev 11(3):601-617

Treviño LK (1992) The social effects of punishment in organizations: a justice perspective. Acad Manage Rev 17(4):647-676

Triplett N (1898) The dynamogenic factors in pacemaking and competition. Am J Psychol 9(4):507-533

Van Yperen NW, Hamstra MR, Van Der Klauw M (2011) To win, or not to lose, at any cost: the impact of achievement goals on cheating. Br J Manage 22:S5-S15

Vandegrift D, Holaday B (2012) Competitive behavior: tests of the n-effect and proximity to a standard. J Neurosci Psychol Econ 5(3):182-192

Vandegrift D, Yavas A (2010) An experimental test of sabotage in tournaments. J Inst Theor Econ 166(2):259-285

Veldhuizen Van Zanten JJ, De Boer D, Harrison LK, Ring C, Carroll D, Willemsen G et al (2002) Competitiveness and hemodynamic reactions to competition. Psychophysiol 39(6):759-766

Vriend T, Jordan J, Janssen O (2016) Reaching the top and avoiding the bottom: how ranking motivates unethical intentions and behavior. Organ Behav Hum Decis Process 137:142-155

Werbach K, Hunter D (2012) For the win: how game thinking can revolutionize your business. Wharton Digital Press, Philadelphia

Zuckerman M (1983) The distinction between trait and state scales is not arbitrary: comment on allen and potkay's 'on the arbitrary distinction between traits and states'. J Pers Soc Psychol 44(5):1083-1086

Publisher's Note Springer Nature remains neutral with regard to jurisdictional claims in published maps and institutional affiliations. 